\title{
IMPLEMENTED STRATEGIES TO HANDLE SEASONAL INVENTORY IN A SUPPLY CHAIN: A CASE STUDY
}

\author{
by \\ Haya Esrar \\ B.Comm. Ryerson University, Toronto, Ontario, 2014 \\ A thesis \\ presented to Ryerson University \\ In partial fulfillment of the \\ requirements for the degree of \\ Master of Science in Management (MScM) \\ in the program of \\ Master of Science in Management
}

Toronto, Ontario, Canada, 2019

(C) Haya Esrar, 2019 


\section{Author's Declaration}

I hereby declare that I am the sole author of this thesis. This is a true copy of the thesis, including any required final revisions, as accepted by my examiners.

I authorize Ryerson University to lend this thesis to other institutions or individuals for the purpose of scholarly research.

I further authorize Ryerson University to reproduce this thesis by photocopying or by other means, in total or in part, at the request of other institutions or individuals for the purpose of scholarly research.

I understand that my thesis may be made electronically available to the public. 


\begin{abstract}
Implemented Strategies to Handle Seasonal Inventory in a Supply Chain: A Case Study Haya Esrar

Master of Science in Management (MScM)

Master of Science in Management

Ryerson University

2019
\end{abstract}

Excess inventory continues to be a growing area of concern for many retailers due to the multitude of issues that arise. This study explores three strategies being practiced by a multinational retailer to help improve its performance measures in handling excess seasonal inventory in various ways. To answer the main research question, a case study method was utilized focusing on one retail organization at three key levels: strategic, warehouse, and retail level. For the purpose of this study, six semi-structured interviews were conducted, along with the collection of some documents in conjunction with personal observations. The results showed a multitude of benefits in using the three strategies and how their proper utilization can aid the retailer in improving its performance in regards to seasonal inventory. In addition to the main findings, three factors were identified that could impact the outcome of these strategies. 


\section{Acknowledgements}

"In the name of God, the Most Gracious, the Most Merciful"

I am indebted to my supervisor, Dr. Hossein Zolfagharinia, for his continued support, patience, and feedback throughout the course of my graduate studies. I would like to acknowledge Dr. Hong Yu for the immeasurable amount of support she has provided, and her kindness in helping a perplexed student. I would also like to thank the professors and staff at Ryerson University who supported me, and provided me with direction during my career as an MScM student.

I am grateful for my peers in the MScM program at Ted Rogers School of Management who have stuck by my side as we completed our journey somewhat together.

Lastly, nobody has been more important to me while I completed this major achievement than my family, Papa, Mama, Bhai, Anni, and Hebah for providing me with nothing but love, guidance, encouragement, unwavering support, and the occasionally much needed verbal thrashing. To the two little ones, Maysa, and Mazan for being my retreat, and accepting the craziness. You have all helped me when I encountered what felt like very difficult days, and for making me who I am today. Thank you. 


\section{Table of Contents}

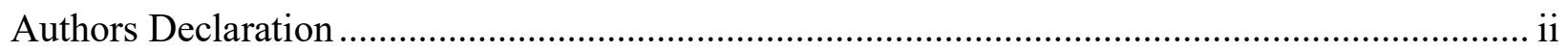

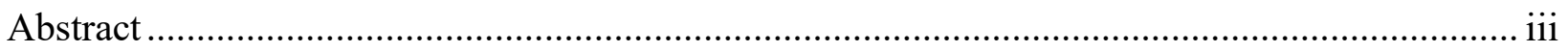

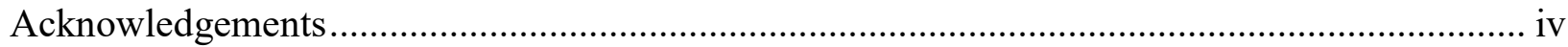

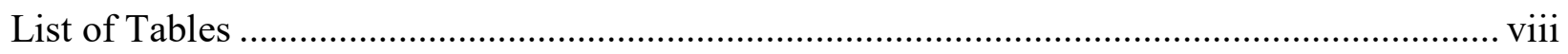



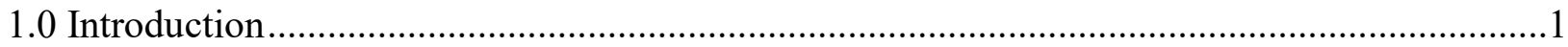



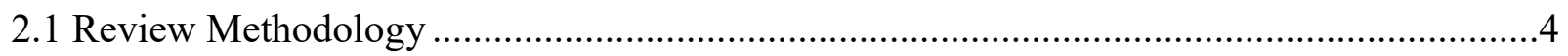

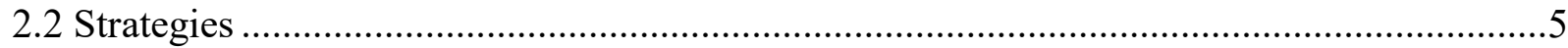

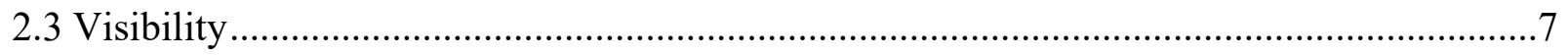

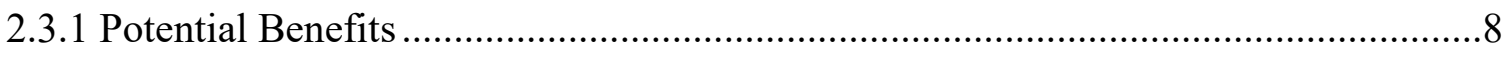

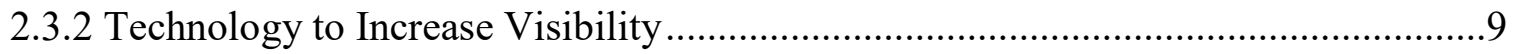

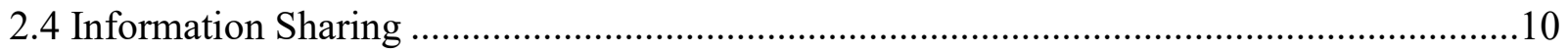

2.4.1 Potential Benefits ........................................................................................11

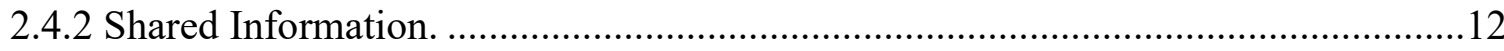

2.4.2.1 Significant Pieces of Information...................................................................13

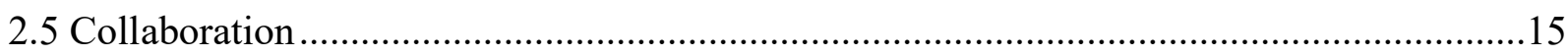

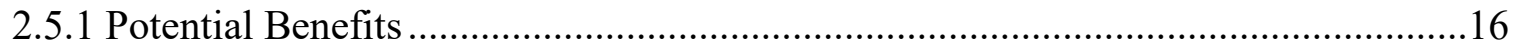

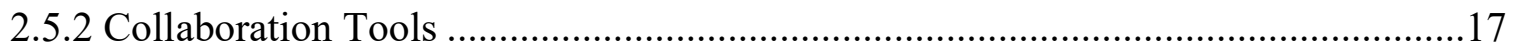

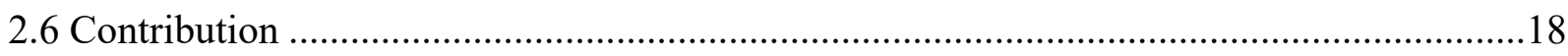

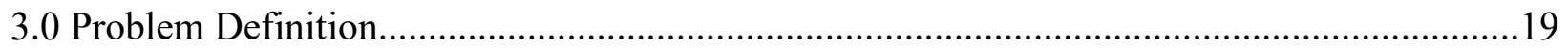

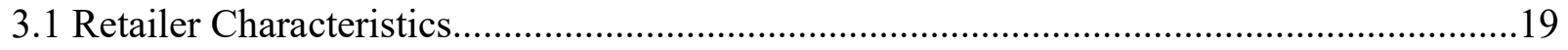

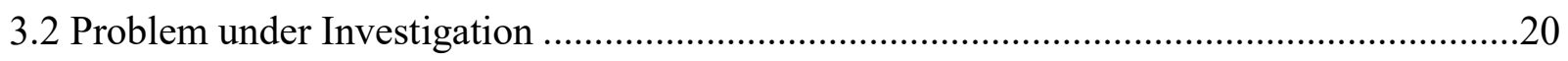

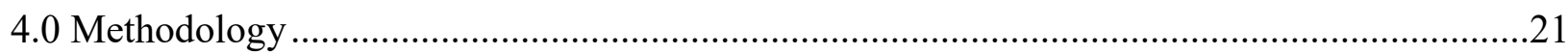

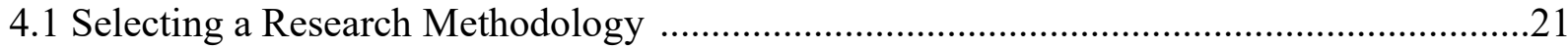

4.1.1 Qualitative and Quantitative Research Methods ..................................................21

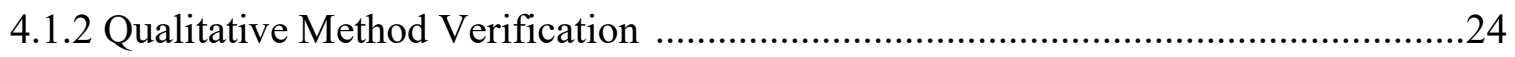

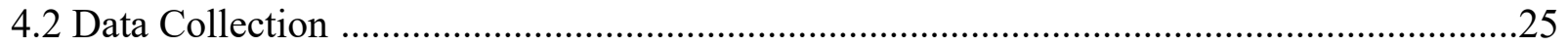

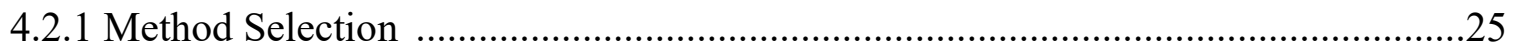




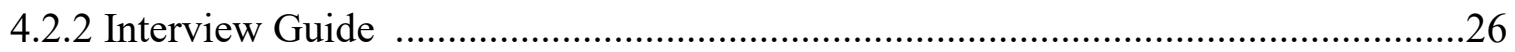

4.2.3 Participant Screening and Recruitment …………............................................28

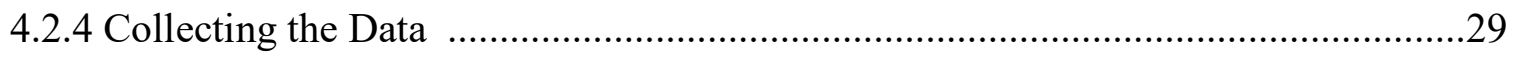

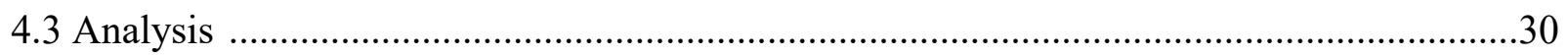

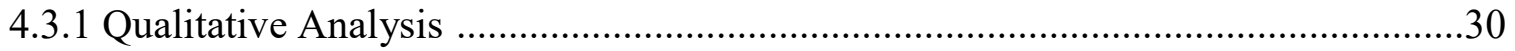

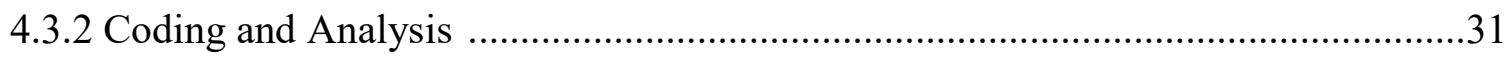

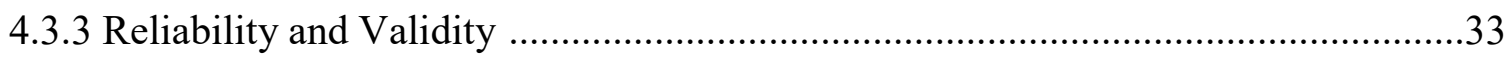

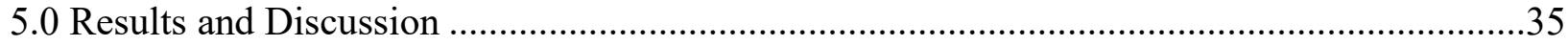

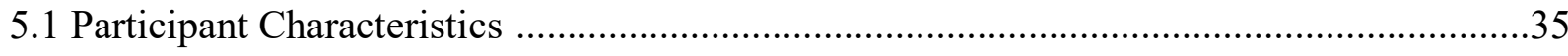

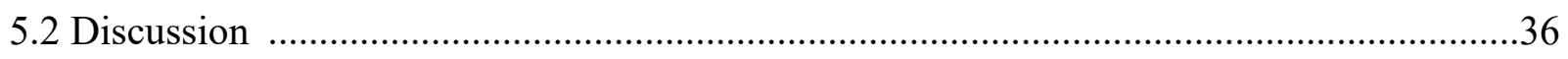

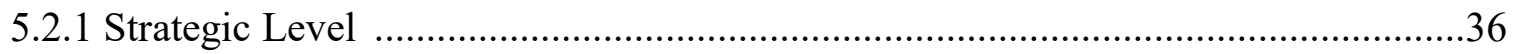





5.2.1.3 Discussion on Collaboration ...................................................................



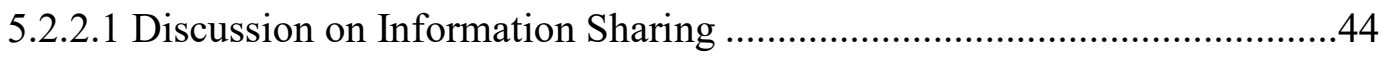

5.2.2.2 Discussion on Visibility ...........................................................................

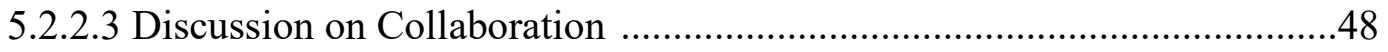



5.2.3.1 Discussion on Information Sharing .......................................................



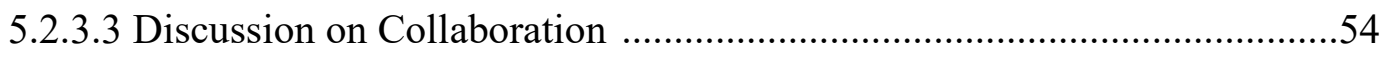

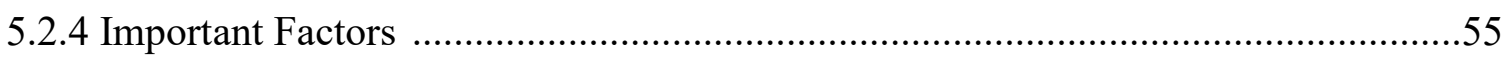

5.2.4.1 Discussion on Human Errors ……………….........................................55

5.2.4.2 Discussion on Communication Gaps .......................................................56

5.2.4.3 Discussion on the Effects Of Decisions on Internal Partners ...................57

6.0 Conclusions, Limitations, and Future Research Avenues …….............................................58

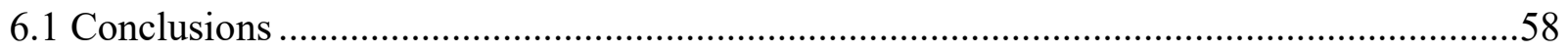

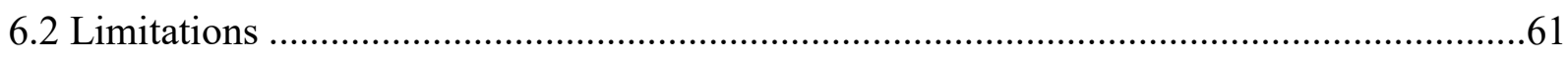






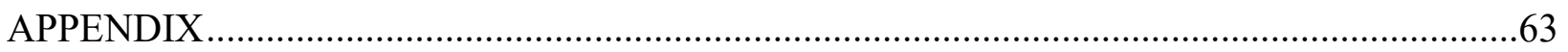

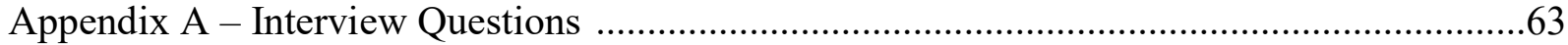

Appendix B - Data Collection Form..........................................................................72

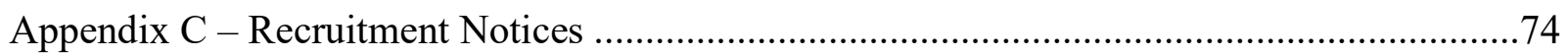

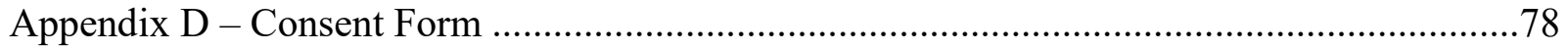

Appendix E - Coder Agreement Form...................................................................... 82






\section{List of Tables}

Table 1 - Key Features in Relevant Studies.......................................................................6

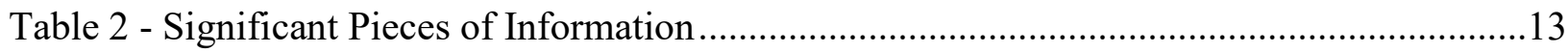

Table 3 - Participant Characteristics .........................................................................................35

Table 4 - Study Findings ..................................................................................................... 


\section{List of Figures}

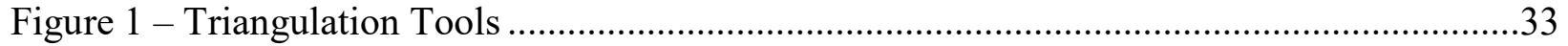

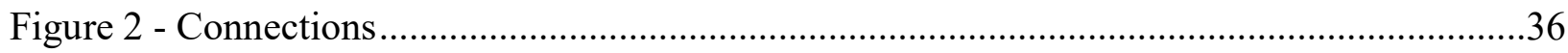


Implemented Strategies To Handle Seasonal Inventory In A Supply Chain: A Case Study

\subsection{Introduction}

As retail organizations begin to face more stringent competition, the need for more efficient and effective supply chain management practices becomes necessary for businesses to remain viable. Supply chain management is a large component of any successful organization as it involves the management of products and assets, fund flows, as well as information (Chopra \& Meindl, 2010). An important division within supply chain is inventory management for which there are many subcategories, all of which perform a vital role in an organizations success.

According to a study conducted on an organizations supply chain, the poor management of a company's supply chain can lead to excessive inventory which can then lead to financial risks (Christopher \& Lee, 2004). Financial risks arise due to a variety of nonrevenue generating methods utilized to reduce inventory from a retail organization shelves. Some methods utilized by retailers to reduce inventory can include bulk selling to a third-party retailer, donating, or destroying the inventory (Miksen, 2017).

Excess inventory which is also referred to as overstock in many studies, has been a growing area of concern for many retailers (Taylor, 2015). Carrying any form of excess inventory raises associated costs (Joshi, 2000) as overstock is labeled as dead weight for any organization since it uses valuable storage space, reduces working capital, and decreases the return on investment (Tersine \& Toelle, 1984). This results in organizations to substantially underperform (Kontuš, 2014) in comparison to their competitors that have a more strategically aligned practice in place. Excess inventory also results in other issues such as misplaced SKUs, which ultimately result in a loss of profit for retailers. Additional inventory leads to more crowded shelves making it more difficult for organizations to keep track of the total number of units available, which can adversely affect profits by $25 \%$ due to misplaced SKUs (Raman, 
DeHoratius, \& Ton, 2001).

Excess inventory, or overstock is estimated to be responsible for nearly " 3.2 percent in lost revenue [...] estimated to cost retailers $\$ 123.4$ billion annually", in North America (Ryan, 2015, para. 2). There are a variety of reasons for excess inventory such as poor forecasting, a lack of flexibility to adjust to changes in demand, and the ordering of additional inventory due to a fear of encountering empty stock (Hendricks \& Singhal, 2009; Bhattacharya, \& Bandyopadhyay, 2011). However, seasonal inventory has a large impact on excess inventory due to its unpredictability and refers to stock that sees a fluctuation in demand due to events, or weather during the year (Melanie, 2017; Cho, 2018). Excess inventory has become a cyclical issue for retailers due to its seasonal nature, forcing retailers to engage different strategies to reduce inventory levels, in order to allow for newer supply. According to Randy Harris, president of Trendex NA, retailers scramble "in a losing effort to salvage the year by selling off inventory at deep discounts" (Marowits, 2014, para. 2).

Inspired by a real world case on the handling of multiple retailers' inventory at the warehouse level, as well as relevant trade articles from within the field, this study was designed focusing on the use of important strategies by a multi-national retailer with significant operations in Canada. The organization that was the focus of this study operates a chain of large discount stores, and super stores. The multi-national retailer has more than ten distribution centres in three main Canadian regions servicing over 400 stores nationwide. For the purpose of this qualitative case study and due to proximity, interviews and observations were conducted at three key levels in the greater Toronto area.

Based on observations, the main research question for this study is: how does information sharing, visibility, and collaboration improve a multi-national retailer's performances in relation 
to the handling of their excess seasonal inventory?

The rest of this thesis is organized as follows. Section 2 presents an overview on the relevant literature. Section 3 provides an outline of the problem and the main question this study aims to answer. Section 4 provides a discussion on the selected research method, the data collection process, and the method of analysis. Section 5 outlines the results from the data collected and provides a discussion on the findings. Lastly, Section 6 concludes with a discussion on the implications, limitations of the study, and potential future research opportunities. 


\subsection{Literature Review}

This section will provide a review on relevant literature and trade articles found on the subject matter. The first section will provide an overview on the review methodology, followed by an introduction to current strategies being practiced by retail organizations in order to highlight possible focus strategies. Subsequent subsections will provide a discussion on the literature on three common strategies in detail, highlighting the definitions of each, the potential benefits of the strategies, and possible tools that are used by organizations.

\subsection{Review Methodology}

This section reviews the literature on three strategies which organizations across various industries currently utilize to streamline their practices and improve performances. The articles were found using Ryerson University and Google Scholars online database which provided access to a wide selection of journals and readings related to the topic. In order to narrow the scope, the literature was mainly collected from journals on supply chain management, management sciences, production economics, operations research, and service operations management. Trade sources and conference papers are also included to gain a broader understanding of the issues currently faced by retailers.

In using the online databases, a combination of the following keywords were used to search for these articles: collaboration, inaccuracy, information sharing, inventory, inventory control, inventory loss, retail, risk, seasonal, seasonal goods, strategies, supply chain, supply chain management, and visibility. Additional references were also found through the literature review within a few of the articles as they provided further knowledge on the topic of discussion. The articles used for this literature review were selected based on the title, abstract, introductory 
sections. In total, 60 relevant references were identified to provide information on the three common strategies and current practices.

\subsection{Strategies}

There are a variety of strategies currently in practice by organizations to increase efficiencies and effectiveness in order to improve business performances. An important aspect of successfully managing an organizations supply chain is in monitoring and measuring information about their key performance and operational parameters (Gunasekaran \& Ngai, 2004). One of the first strategies found in the literature was the implementation of information systems and providing continuous information on these key parameters and the positive affect it has on an organizations performance (Qrunfleh \& Tarafdar, 2014).

Additional strategies included coordination amongst multiple partners both internal and external in order to gain a competitive advantage and improve performances (Dyer \& Singh, 1998). Poor coordination can result in weak operational performances with consequences such as higher inventory costs, lower customer service, higher overall costs, and longer delivery times (Lee, Padmanabhan, \& Whang, 1997; Simatupang, Wright, \& Sridharan, 2002).

According to the literature and numerous trade articles, there were three reoccurring strategies that were identified to be the focus of many studies. Each of these studies focused on one primary strategy in mostly one singular context. The three most frequently discussed tangible strategies in the literature amongst various industries are: (1) visibility, (2) information sharing, and (3) collaboration within the supply chain, however, few studies touch upon the role of excess seasonal inventory within a retail context. Table 1 depicts the key features in the most relevant studies, highlighting each studies discussion on seasonal inventory, the discussed 
strategies, as well as whether the paper was completed using a retail organizational context.

Table 1.

Key features in the most relevant studies.

\begin{tabular}{|c|c|c|c|c|c|c|}
\hline \multirow[t]{2}{*}{ Author(s) and date } & \multirow[t]{2}{*}{ Method of Analysis } & \multicolumn{2}{|c|}{ Seasonal Inventory } & \multirow[t]{2}{*}{ Strategies } & \multicolumn{2}{|c|}{ Retail } \\
\hline & & Yes & No & & Yes & No \\
\hline Chen et al. (2000) & Mathematical model & & $\mathrm{X}$ & $\mathrm{IS}^{\mathrm{a}}$ & $\mathrm{X}$ & \\
\hline Joshi (2000) & Simulations & & $\mathrm{X}$ & IS & $\mathrm{X}$ & \\
\hline Huang et al. (2003) & Qualitative & & $\mathrm{X}$ & IS & $\mathrm{X}$ & \\
\hline Cachon (2004) & Mathematical model & & $\mathrm{X}$ & $\mathrm{C}^{\mathrm{b}}$ & & $\mathrm{X}$ \\
\hline Christopher and Lee (2004) & Archival data & $\mathrm{X}$ & & $\mathrm{V}^{\mathrm{c}}$ & $\bar{X}$ & \\
\hline Holweg et al. (2005) & Case studies & $\bar{X}$ & & $\mathrm{C}$ & $\mathrm{X}$ & \\
\hline Quirk \& Borrello (2005) & Qualitative & & $\mathrm{X}$ & $\mathrm{V}$ & $\mathrm{X}$ & \\
\hline Chow at al. (2006) & Case studies & & $\mathrm{X}$ & $\mathrm{V}$ & $\mathrm{X}$ & \\
\hline Closs and Nair (2006) & Monte-Carlo simulation & $\mathrm{X}$ & & $\mathrm{C}$ & $\mathrm{X}$ & \\
\hline Daugherty et al. (2006) & Survey and industry cases & & $\mathrm{X}$ & $\mathrm{C}$ & $\mathrm{X}$ & \\
\hline Enslow (2006) & Industry survey & & $\mathrm{X}$ & $\mathrm{V}$ & & $\mathrm{X}$ \\
\hline Geary et al. (2006) & Qualitative & & $\mathrm{X}$ & IS & $\mathrm{X}$ & \\
\hline Zhang et al. (2006) & Mathematical model & & $\mathrm{X}$ & IS & $\mathrm{X}$ & \\
\hline Bartlett et al. (2007) & Case study & & $\mathrm{X}$ & $\mathrm{V}$ & $\mathrm{X}$ & \\
\hline Tajima (2007) & Qualitative & & $\mathrm{X}$ & $\mathrm{V}$ & $\mathrm{X}$ & \\
\hline Yücesan (2007) & Industry survey & & $\mathrm{X}$ & IS & & $\mathrm{X}$ \\
\hline Zhou \& Benton (2007) & Survey & & $\mathrm{X}$ & IS & & $\mathrm{X}$ \\
\hline Choi et al. (2008) & Virtual Enterprise Chain & & $\mathrm{X}$ & $\mathrm{C}$ & & $\mathrm{X}$ \\
\hline Francis (2008) & Qualitative & & $\mathrm{X}$ & $\mathrm{V}$ & & $\mathrm{X}$ \\
\hline Lumsden and Mirzabeiki (2008) & Qualitative & & $\mathrm{X}$ & IS & & $\mathrm{X}$ \\
\hline Chopra and Meindl (2010) & & & $\mathrm{X}$ & & & $\mathrm{X}$ \\
\hline Sarac et al. (2010) & Qualitative & & $\mathrm{X}$ & $\mathrm{V}$ & $\bar{X}$ & \\
\hline Koçoğlu et al (2011) & Mixed methods & & $\mathrm{X}$ & IS & & $\mathrm{X}$ \\
\hline Mentzer et al. (2011) & & & $\mathrm{X}$ & IS & & $\mathrm{X}$ \\
\hline Zhang et al. (2011) & Mathematical model & & $\mathrm{X}$ & $\mathrm{V}$ & & $\mathrm{X}$ \\
\hline Cho and Lee (2013) & Modelling (SARMA) & $\mathrm{X}$ & & IS & $\mathrm{X}$ & \\
\hline Lee et al. (2013) & Archival data & & $\mathrm{X}$ & $\mathrm{V}$ & & $\mathrm{X}$ \\
\hline No author (2014) & & & $\mathrm{X}$ & $\mathrm{V}$ & & $\mathrm{X}$ \\
\hline Heckmann et al. (2015) & Qualitative & & $\mathrm{X}$ & $\mathrm{C}$ & & $\mathrm{X}$ \\
\hline Rekik at al. (2015) & Simulation & & $\mathrm{X}$ & $\mathrm{V}$ & $\mathrm{X}$ & \\
\hline Sari (2015) & Simulation & $\mathrm{X}$ & & $\mathrm{C}$ & $\mathrm{X}$ & \\
\hline Taylor (2015) & Industry analysis & $\mathrm{X}$ & & & $\mathrm{X}$ & \\
\hline Huong Tran et al. (2016) & & & $\mathrm{X}$ & IS & & $\mathrm{X}$ \\
\hline Lee and Rim(2016) & Mathematical model & & $\mathrm{X}$ & $\mathrm{V}$ & $\mathrm{X}$ & \\
\hline Wang and Disney (2016) & Qualitative & & $\mathrm{X}$ & IS & $\mathrm{X}$ & \\
\hline Current Study & Case Study & $\bar{X}$ & & $\mathrm{~V} / \mathrm{IS} / \mathrm{C}$ & $\mathrm{X}$ & \\
\hline $\begin{array}{l}\text { a IS: Information Sharing } \\
{ }^{\mathrm{b}} \mathrm{C} \text { : Collaboration } \\
{ }^{\mathrm{c}} \mathrm{V} \text { : Visibility }\end{array}$ & & & & & & \\
\hline
\end{tabular}




\subsection{Visibility}

According to a study conducted by the Aberdeen Group on analyzing key improvement areas for supply chain organizations, supply chain visibility was found to be a top concern for approximately $79 \%$ of the large companies (Enslow, 2006). A lack of visibility in a supply chain results in an increase in inventory levels (Challenges in Supply Chain Visibility, 2014) since organizations begin to carry additional inventory in the case it is needed. Carrying additional inventory also results in an increase in associated carrying costs, all of which negatively affect the organizations bottom line. The high percentage of organizations concerned with visibility is corroborated by other literature as well, as researchers seek to understand the role of visibility in supply chain processes and the benefits it poses to organizations.

Visibility in the supply chain has a significant role within the industry as it enables an organization to become more cognizant of their practices. However, despite the significance of visibility and the studies conducted using this strategy, there is a wide array of proposed definitions for the term which results in confusion. Based on a study conducted by Francis (2008) in which they examined previously proposed definitions of the term supply chain visibility, they were able to provide readers with a more exact definition. Francis' detailed definition is that "supply chain visibility is the identity, location and status of entities transiting the supply chain, captured in timely messages about events, along with the planned and actual dates/times for these events" (Francis, 2008, p.3). Having one, clear definition for the term allows for consistency throughout the remainder of the paper and concedes for a better understanding of the studies conducted using the term in various contexts. The following subsection will provide a discussion on the benefits of visibility and its role in organizations in order to gain a deeper understanding. 


\subsubsection{Potential Benefits}

Visibility is noted to be an essential strategy to be used for supply chains to improve their overall performance (Lee, Kim \& Kim, 2014). Visibility can be achieved through a variety of ways such as through teamwork between suppliers and customers working together as was studied by Bartlett, Julien and Baines (2007). A similar concept can be applied across various supply chain partners in order to create visibility across different functions. According to a study completed by Christopher and Lee (2004), end-to-end visibility would lessen supply chain risks and also increase confidence amongst supply chain managers in proportion to the quality of the information shared. The increase in confidence and decrease in risk would arise from all the partners within the supply chain having clear visibility in all the necessary areas. For example, Christopher and Lee (2004) depict the severity of limited visibility in a supply chain was when a sales team believes the fulfillment times are unreliable, thus they develop a plan to address the issue on their own by ordering additional buffer stock. The lack of visibility for the sales team resulted in the organization owning more stock than was necessary which would generate higher inventory carrying costs.

Visibility has a significant impact on inventory as it provides organizations with the most current and accurate data regarding their inventory (Zhang, Goh, \& Meng, 2011) allowing for more efficient and effective inventory practices. Visibility in specific areas such as current, and in-transit inventory help optimize processes as the company becomes more cognizant of both the upstream and downstream flow of inventory within the supply chain. An organizations awareness of their own inventory allows for better decision making since it decreases variability, and thus reducing inventory levels. As competition has become more stringent and technology has evolved, many organizations have introduced technology based tools to increase visibility 
which will be discussed in the next subsection.

\subsubsection{Technology to Increase Visibility}

Technology has become a vital tool for many organizations to implement within their supply chain processes. Due to the continuous improvements and customizable ability of technology, organizations are able to create efficiencies in their supply chain practices. For example, tools such as radio frequency identification commonly referred to as RFID "is a wireless technology that allows for automated remote identification of objects" (Bolic, Athalye, \& Li, 2010, p. 4). The use of radio frequency technology continues to be an increasingly growing area of research due to its benefits. According to a few of these many studies conducted, the proper implementation of RFID allows organizations benefits such as real-time product visibility, an increase in process improvements, a reduction in distribution costs, reduced stock outs, and lower storage costs (Chow, Choy, Lee, \& Lau, 2006; Tajima, 2007; Sarac, Absi, \& Dauzère-Pérès, 2010). Studies conducted by Quirk and Borrello (2005) and Tajima (2007) noted that the implementation of RFID enables higher visibility thus having the potential to increase productivity by $15 \%$ and reduce supply chain costs. The proper implementation and continuous use of this specific technology has shown positive outcomes for organizations and results in an increase in visibility.

A study conducted by Rekik, Syntetos, \& Jemai (2015) acknowledged that the implementation of RFID for both centralized and decentralized supply chains had noted benefits such as higher visibility, which resulted in a decrease of costs for a variety of different channels for a retailer. Their study was important as it focuses on an emerging area of retailing and touches upon the differences in supply chain operations for different channels, such as eretailing. It was noted how despite the different channels and operating practices, the application 
of RFID provided similar benefits.

Another tool mentioned in the literature to increase an organizations visibility is the implementation of an enterprise resource planning system, also referred to as an ERP. An ERP is a system that manages the information and data requirements of an organization (Shtub, 1999). The implantation of an ERP system has become popular due to the benefits it provides such as improving operational efficiency and effectiveness by integrating an organization processes with better access to data along the chain (Chou \& Chang, 2008).

An additional tool mentioned in the literature and trade articles is the use of a point-ofsale system. The point of sales system is the place in which the customer executes the payment for the goods or services provided by an organization (Guinn, 2018). The point of sale system provides visibility for multiple partners and allows for more opportunities to increase efficiencies and produce new revenue potential (Intelligent retailing: POS helps do more with less, 2018). Visibility in the supply chain has a significant role as it allows an organization to become more cognizant of their practices. Another common strategy cited in the literature is information sharing which will be discussed in the next section.

\subsection{Information Sharing}

There are many studies that have been conducted on the importance of information sharing in a supply chain. Despite the significance of information sharing and the many studies that have been conducted, there are a variety of similar definitions due to the context it is used in. For the purposes of this study a concise definition for information sharing was taken from Huong Tran, Childerhouse, \& Deakins (2016) in which they defined supply chain information sharing as the extent to which proprietary and critical information is shared between supply chain members 
(Koçoğlu, İmamoğlu, İnce, \& Keskin, 2011) and a "willingness to make strategic and tactical data available to other members of the supply chain" (as cited in Mentzer, 2001, p.11). In referring to and combining the different sources for the definition of the term, this allows for consistency throughout the remainder of the paper to ensure a better understanding of the studies completed on information sharing in the different contexts it has been used in.

Information sharing is an effective strategy to reduce errors made through the supply chain and can involve sharing a combination of information, depending on the level within the chain. For example, sales information can be shared with manufacturers so they are able to better prepare for future orders, or even through a vendor managed inventory system in which vendors take responsibility of maintaining an agreed upon level of inventory (Huang, Lau, \& Mak, 2003; Yücesan, 2007). The following subsection will present a discussion on the benefits of information sharing.

\subsubsection{Potential Benefits}

A major risk in inventory management is the bullwhip effect. The bullwhip effect was initially introduced as the variance or demand amplification effect by Forrester (1958) using an industrial dynamics approach. The bullwhip effect refers to the phenomenon in which order variability increases as customer orders move upstream within a supply chain (Geary, Disney, \& Towill 2006; Wang \& Disney, 2016). This effect can be applied to the retail industry as there is an inclination within the industry to miscalculate customer demand which results in either overstock or understock thus resulting in significantly negative consequences. According to studies on the bullwhip effect by Chen, Drezner, Ryan, and Simchi-Levi (2000) and Holweg,

Disney, Holmstrom, \& Smaros (2005), information sharing is indicated to be a main factor in controlling the bullwhip effect as it can significantly reduce the variability that arises from 
seasonal demands. This can occur between many different levels of supply chain such as: the customer and retailer, the retailer and supplier, the retailer and a third-party logistics firm, the supplier and a third-party logistics firm, which can all lead to better decision making on ordering, planning, and the allocation of inventory, all of which can aid organizations in reducing excess inventory.

Information sharing was a strategy also suggested by Cho and Lee (2013). They used a quantitative method to analyze how an increase in information sharing results in a decrease in inventory and supplier costs for a supply chain, specifically during seasonal occurrences. In noting the benefits of information sharing, it is also important to understand the different pieces of information that are valuable.

\subsubsection{Shared Information}

In reviewing the literature many researchers discussed the merit of various pieces of information that can be shared amongst different partners in the supply chain. Lumsden and Mirzabeiki (2008) conducted a study evaluating the value of different information types such as the condition of the product while it is in transit, the position of inventory, and history of sales and for different supply chain partners. Other studies by Zhang, Tan, Robb, and Zheng (2006) and Cho and Lee (2013) addressed the valuable pieces of information such as sharing shipping quantity information and sharing retailer demand information. Table 2 below summarizes the

different pieces of information and the supply chain partners that would most benefit. The next subsection provides a description for each of the pieces of information mentioned in Table 2. 


\section{Table 2.}

The significant pieces of information and the supply chain partners that would most benefit

\begin{tabular}{|l|c|c|c|}
\hline & \multicolumn{3}{|c|}{ Supply Chain Partners } \\
\hline \multicolumn{1}{|c|}{ Significant Pieces of Information } & Supplier & Retailer & Customer \\
\hline I. Condition of products while in shipment & $\mathrm{X}^{\mathrm{a}}$ & $\mathrm{X}$ & $\mathrm{X}$ \\
\hline II. History of sales & $\mathrm{X}$ & $\mathrm{X}$ & \\
\hline III. Position of products in inventory & $\mathrm{X}$ & $\mathrm{X}$ & $\mathrm{X}$ \\
\hline IV. Retail point-of-sales information & $\mathrm{X}$ & $\mathrm{X}$ & \\
\hline V. Retailers demand & $\mathrm{X}$ & & \\
\hline VI. Retailers inventory levels & $\mathrm{X}$ & $\mathrm{X}$ & $\mathrm{X}$ \\
\hline VII. Shipment quantity information & & $\mathrm{X}$ & $\mathrm{X}$ \\
\hline VIII. Warehouse operations & $\mathrm{X}$ & $\mathrm{X}$ & \\
\hline
\end{tabular}

${ }^{\mathrm{a}} \mathrm{X}$ : Present in study

Note. Table adapted from Lumsden and Mirzabeiki (2008). I, II, III, IV, VI, VII from Lumsden \& Mirzabeiki (2008). V from Cho \& Lee (2013). VII from Zhang et al (2006).

\subsubsection{Significant pieces of information}

This subsection provides a description for each of the pieces of information mentioned in Table 2 and its value for the three supply chain partners.

\section{Condition of products while in shipment}

The condition of the products while in shipment is important for each of the three partners mentioned in Table 2 due to the different shipping needs of different products. Some of the items in shipment may require different temperature settings, or it could also be a higher value item. This information is also important in order to hold each of the partners accountable in the case of a fault (Lumsden \& Mirzabeiki, 2008).

\section{History of sales}

The history of sales is important for the retailer as it can help with better decision-making in regards to inventory ordering including: frequency, batch size, and the number of orders. This information can also be helpful for suppliers and manufacturers so they have the ability to better 
plan for future production (Lumsden \& Mirzabeiki, 2008).

\section{Position of products in inventory}

The position and sequence of the products in inventory adds value for the retailers especially as it allow them to become more cognizant of the location of the inventory. This value is also added to the manufacturer and supplier as correct knowledge of the inventory can improve inventory practices (Lumsden \& Mirzabeiki, 2008). An improvement in inventory practices enables better time efficiency thus reducing costs (Bowersox, Closs, \& Cooper, 2007).

\section{Retail point-of-sales information}

This information adds value for suppliers, manufacturers, and retailers as the retail pointof-sales provides the partners with the most current information. In having the most current sales information, benefits for each partner include lower inventory costs and lower order costs as each partner can place orders or send orders in to production as soon as the item is sold and the quantity decreases at the supplier and retail level (Lumsden \& Mirzabeiki, 2008).

\section{Retailers demand}

This information is valuable for manufacturers and suppliers as they are able to begin production, and ship out accordingly based on the retailers demand (Cho \& Lee, 2013). Having the retailers demand information available ensures the on-time availability of inventory.

\section{Retailers inventory levels}

This information can add value for all three partners mentioned in Table 2 . This information is important for customers so they are aware of retail product availability and can choose to shop accordingly. For retailers, it is essential to be aware of the products that are available for sale in order to generate sales. For suppliers and manufacturers, the retailer's inventory levels can allow for more accurate inventory control, improve order processing times, 
as well as schedule shipments accordingly (Lumsden \& Mirzabeiki, 2008).

\section{Shipment quantity information}

According to Lumsden and Mirzabeiki (2008), sharing the shipping quantity information allows customers to be more aware of their orders, and in the situation the order quantity is not correct, customers have the ability to adjust and resolve any future orders. Similarly, Zhang et al. (2006) noted that shipment quantity information adds value for retailers and manufacturers, as it will allow them more time to resolve and adapt to any shipping uncertainties that arise when the shipment quantities differ from what is expected.

\section{Warehouse operations}

According to a study completed by Bowersox et al. (2007) warehouse operations information adds value for retailers, manufacturers, and suppliers as each partner becomes aware of the different receiving time of the inventory, and the order quantities. This allows for more efficiency in between the partners.

Information sharing has a significant role within retail as it allows an organization to create efficiencies within their supply chain practices thus reducing errors and costs.

\subsection{Collaboration}

A supply chains performance is affected by the allocation of inventory risk and the various strategies utilized by organizations to reduce these risks. Risk is defined as a variation in supply chain outcomes, and its values (Heckmann, Comes, \& Nickel, 2015). According to studies by Cachon (2004) and Sari (2015), a strategy to reduce risks is collaboration. Both studies suggest that collaborating supply chain resources between various supply chain partners creates an environment of support and also aids in reducing overall inventory levels. 
According to Daugherty et al. (2006) collaboration within a supply chain environment occurs when two or more independent companies work together to jointly achieve greater success than what can be achieved by just working alone. Working together in synergy is expected when independent companies work together focusing on both operational and strategic competencies. Utilizing a company's individual core competencies will aid in strengthening the whole supply chain.

\subsubsection{Potential Benefits}

Collaboration can occur amongst many different levels of an organization, each with its own benefits. Choi, Kang, Chae, and Kim (2008) created a value chain framework to function as a guide for organizations to promote collaboration which included factors such as responsiveness, and creating a focus on customers. This framework focuses mainly on seamlessly integrating all the different processes and factors in order to meet business objectives so organizations are able to make more strategic and reliable decisions in regards to inventory.

Another form of collaboration in the literature is between the ordering and replenishment of inventory based on the performance of seasonal items (Closs \& Nair, 2006). This strategy is suggested as way to reduce the shelving space required by bulk purchased seasonal items and to avoid profit loss due to discounting items. The common method of acquiring seasonal goods is to order the required number of units and pay minimal transportation costs. If the item does not sell during the season for which it was intended for, retailers are forced to use nonrevenue generating methods to clear the inventory off of the shelves. Some of these methods include reducing the price of these items, bulk selling to an outlet retailer, donating, or destroying the inventory. Using the suggested method entails a closer collaboration between retailers and suppliers and will aid in the reduction of inventory levels which will reduce the need to utilize the nonrevenue 
generating methods.

Based on the available literature and studies conducted, collaboration between different levels of an organization can help strengthen the supply chain (e.g., Daugherty et al., 2006) and improve performances. In noting the benefits, there are a variety of tools that organizations utilize to aid in collaboration amongst various partners.

\subsubsection{Collaboration Tools}

In reviewing the literature and trade articles, three common collaboration tools were noted. The first was CPFR, collaborative planning, forecasting, and replenishment in which retailers and suppliers work together to ensure customer demands are met by real time inventory updates and future demand requirements (Seifert, 2003; Cho \& Lee, 2013) to ensure an efficient supply chain process.

Another collaborative system is ECR, efficient consumer response. This method involves collaboration between manufacturers and retailers, in an effort to improve supply chain performances through coordinating in areas such as production, replenishment, and marketing. (Cho \& Lee, 2013; Introduction: Collaborative Planning, Forecasting and Replenishment, 2011).

Finally, a common method used by many retail organizations is VMI which is a vendormanaged inventory system (Cho \& Lee, 2013) in which the manufacturer or supplier is responsible for all the decisions in regards to a retailers inventory. This system has become more prominent due to its benefits such as a reduction in inventory costs, and improved customer service as a result of reduced order times (Yao, Evers, \& Dresner, 2007). 


\subsection{Contribution}

Based on the available literature, it was noted that there was a gap to be filled with this research. There are many studies, as listed above in Table 1, which discuss the three focus strategies of this research. However, from the ones reviewed, only six of the available studies touch upon the role of seasonal inventory in a retail context. This research will reduce the knowledge gap in the existing literature by examining which strategies and to which extent they are used by the retail organization to improve performances by the handling of their excess seasonal inventory.

This research is unique as it was designed utilizing a case study method focusing on one retail organization at three key different levels. The three levels were selected on the basis of key functions within the organization and included participants at a strategic level, managers at the warehouse level, and managers at the retail store level (Juneja, n.d.). These three levels were chosen to gain a deeper understanding of the functions and processes of each level, and to understand the working relation amongst the different levels. This research is also unique in that it is conducted in a Canadian context through the collection of primary data, which is collected primarily through semi-structured interviews. The Canadian context is especially interesting due to the multi-cultural demographics of the country. According to the 2016 census, there are more than 250 different ethnicities people identify as in Canada (Statistics Canada, 2017). In order to reach a diverse market, retailers need to ensure they are able to focus the right products towards the different ethnicities at the right time (Understanding the Power of Ethnic Consumers in Canada, 2018). 


\subsection{Problem Definition}

Defining an issue or problem is the first step in designing any study regardless if it is conducted using qualitative or quantitative methods (Creswell, 2007). The purpose of this section is to discuss the characteristics of the retailer which is the focus of the study, and provide details on the problem under investigation.

\subsection{Retailer Characteristics}

Inspired by a real-world case on the handling of multiple retailers' inventory at the warehouse level, as well as relevant trade articles from within the field, this study was designed focusing on the use of important strategies by a multi-national retailer with significant operations in Canada. The organization that is the focus of this study operates a chain of large discount stores, and super stores which also includes groceries. The multi-national retailer operates more than 400 brick and mortar locations across Canada, of which approximately 300 are larger super stores and more than 60 are discount type stores. In order to effectively and efficiently provide the stores with merchandise, the retailer operates more than ten distribution centres strategically located in three main Canadian regions.

The retailer operates on three main levels including; the strategic or head office, the distribution warehouses, and the retail level. For this organization, each of the levels are autonomous with their individual key performance measures such as; cost of inventory at the strategic level, cases per hour and inventory turnover at the warehouse level, and sales and productive inventory rates at the retail level. However, each of the levels work together to ensure they are able to meet and exceed the measures in place.

The retailer carries a deep variety and assortment of merchandise along different 
departments, making it easier for customers to complete their shopping in one place. The retail organization also takes part popular seasonal events such as: Back to School, Thanksgiving, Halloween, Christmas, and Canada Day. In conjunction with these major seasonal events, retail stores also take part in community ethnic events which are assigned based on demographics. These ethnic events include but are not limited to Chinese New Year, Diwali, and Eid.

\subsection{Problem under Investigation}

With the retailer offering a multitude of basic and both regular and ethnic seasonal inventory, the organization has to deal with any excess which they are unable to sell. Excess inventory, also referred to as overstock has been a growing area of concern for many retailers (Taylor, 2015) due to the multitude of issues that arise. Carrying any type of excess inventory can raise associated costs (Joshi, 2000) as it uses valuable storage space, reduces working capital, and decreases the return on investment (Tersine \& Toelle, 1984). This results in organizations to substantially underperform (Kontuš, 2014) in comparison to their competitors that have a more strategically aligned practice in place. Excess inventory also leads to more crowded shelves making it more difficult for organizations to keep track of the total number of units available, which can adversely affect profits by $25 \%$ due to misplaced SKUs (Raman, DeHoratius, \& Ton, 2001).

A majority of the seasonal inventory carried by the retailer which is the focus of this study include items such as: barbeques, patio sets, reusable Christmas trees, and outdoor festive lights. As excess inventory is estimated to cost retailers in North America approximately $\$ 123$ billion annually in lost revenue (Ryan, 2015), this is a crucial area for organizations to focus on. Based on this and initial observations, the main research question is: how does information 
sharing, visibility, and collaboration improve a multi-national retailers performances in relation to the handling of their excess seasonal inventory? The next section will discuss the methodology for studying the above-mentioned problem to answer the main research question. 


\subsection{Methodology}

This section will focus on the approach with which this research was conducted. The first part will discuss the selection of a qualitative method for this research opposed to a quantitative approach. The second part will provide a discussion on the data collection methods, and participant recruitment, followed by an overview on the steps taken to conduct the analysis as well as a discussion on reliability and validity.

\subsection{Selecting a Research Methodology}

Conducting research is an integral form of generating new knowledge or expanding on an existing base. In reviewing multiple studies, the discussion on qualitative and quantitative methods was noted frequently. This section will discuss the selection of a qualitative approach for this study by first discussing key characteristics of both research approaches.

\subsubsection{Qualitative and quantitative research methods}

Throughout different industries quantitative research methods are categorized as empirical studies or statistical studies (Newman \& Benz, 1998). This form of research involves collecting numerical data through standardized steps that can be translated into a form of statistics that is used to see a larger picture through the testing of proposed hypotheses. As quantitative methods follow a more standardized research process, it is considered to be better suited to larger, representative sample sizes in order to effectively extrapolate results. One noted disadvantage or criticism of quantitative studies is that the studies become too narrow to be considered entirely useful (Nielsen, 2004) and can sometimes become misleading due to number fetishism, a term used by deLarminat, which can sometimes be used to manipulate numbers in order to reduce uncertainties (deLarminat, 2013). In other views, quantitative research is also 
seen to be dismissive of individual experiences and can fall victim to generalization (Hammarberg, Kirkman, \& Lacey, 2016) as not all experiences are measurable by a numeric value. In cases like these the use of quantitative research may limit the findings, which could encourage the use of an alternative method better suited to the main research question such as qualitative research.

Qualitative methods are used when a problem or issue needs to be explored (Creswell, 2007) and although varying definitions with similarities are seen in the literature, Strauss and Corbin state that qualitative research is "any type of research that produces findings not arrived at by statistical procedures or other means of quantification" (as cited in Yilmaz, 2013, p. 311). Based on this definition, qualitative research is focused more on understanding trends by examining experiences and opinions of individuals.

However similarly to quantitative methods, there are some criticisms towards qualitative methods. Qualitative research is seen as subjective due to the researchers' personal involvement and emic perspective (Yilmaz, 2013). A second disadvantage of this method is that the findings may not necessarily extend to a wider population or cases (Atieno, 2013; Yilmaz, 2013). However, the goal of qualitative research is not to generalize; rather it is to explore and understand a problem or issue through cases in context (Creswell, 2007). Another common criticism towards qualitative methods seen in the literature is the reliability and validity of a research conducted qualitatively, this will be further discussed in Section 4.1.2.

The main focus of this study is inductive as it is trying to gain a deeper understanding of strategies being practiced by a retailer to improve performances for the handling of their excess seasonal inventory through the use of the designed interview questions. The selection of a research methodology is inherently dependent on the nature of the research question used. For 
the purpose of explorative studies similar to this work, qualitative methods are deemed to be an appropriate approach (Neuman, 2014). Rather than relying on numbers and quantifiably measuring the strategies, this research was designed through the use of open-ended interview questions towards a select number of participants to explore individual perspectives at different levels within the organization.

\subsubsection{Qualitative method verification}

Validity and reliability are two factors which any researcher should concern themselves with when designing a study regardless of the method selected, as they are both key points in persuading readers that the research findings are worth paying attention to (Golafshani, 2003). For the purpose of this study, matters surrounding qualitative research are discussed below.

Validity refers to truthfulness and how accurately the designed study measures what it is supposed to measure (Neuman, 2014). In other terms, the purpose of validity is to ensure that that the study is authentic, honest, and fair rather than focusing on a singular truth (Neuman, 2014; Noble \& Smith, 2015). However in a study conducted using qualitative methods, especially one designed using explorative methods or grounded theory, the measurement of validity is a little more difficult. Therefore, for the purposes of validity in a qualitative study, it is important that any data collected and observations are an apt fit to the theories that are produced from them (Maxwell, 2009). It is important that the knowledge produced is well grounded in the data that has been collected to ensure the research has validity. This means that examples are used to support the findings, and similar to reliability, it is important to keep in mind the relevant context the data was conducted from (Lampard \& Pole, 2015).

Reliability refers to the consistency or dependability of a research (Neuman, 2014) and is a measure of whether the replication of the study by another researcher would yield the same 
result (Golafshani, 2003). Although difficult, reliability can be achieved in many different ways in a qualitative study. Combining a diverse set of tools and techniques is beneficial for qualitative research as it enables the researcher to illuminate the different dimensions of a case without neglecting any key aspects that could be otherwise ignored (Neuman, 2014). The following section will describe the used approach in the data collection.

\subsection{Data Collection}

This following section will explain the use of semi-structured interviews and observations, the type of questions that were asked, how participants were found, screened, and included to take part in this study, as well as how the interviews were conducted.

\subsubsection{Method selection}

There are many different forms through which qualitative data can be collected. Some of the more commonly used methods of data collection include observations, interviews, and documents (Neuman, 2014). For the purpose of this research, semi-structured interviews were conducted, along with the collection of some documents in conjunction with personal observations.

Due to the nature of the research question, the use of semi-structured interviews were deemed to be an appropriate choice as this approach is adequately structured to address specific elements of the research question and it also allows for flexibility as it leaves an opportunity for participants to expand and offer new insights (Galletta, 2013). Semi-structured interviews focus on the views and experiences of the participants which, for the purpose of this research were important as one retail organization across three main levels were being studied. In addition, this method was also selected as the primary method of data collection as according to Bernard 
(2008) semi-structured interviews are best used when there may not be more than one opportunity to interview a participant (as cited in Cohen \& Crabtree, 2006) due to the availability of the research participants. The use of a structured interview may have decreased the possibility of understanding certain topics as semi-structured interview allows for elaboration while still following a clear structure and information that would have otherwise been acquired through potential multiple interviews can be gleaned from one meeting.

In addition to semi-structured interviews, observations were also used as a form of data collection. Schensul, Schensul, and LeCompte (1999) define observation as "the process of learning through exposure to or involvement in the day-to-day or routine activities [...] in the

researcher[s] setting" (as cited in Kawulich, 2005, p. 2). Observations enable the researcher to gain a deeper understanding of the activities and processes that are taking place. For the purpose of this research study observations were made at the retail store and the warehouse level.

A final method of collecting data was through the use of documentation voluntarily provided by the participants. These documents were provided as a form of visual examples to reiterate what was said during the interviews. Documents are used as a form of supplementary research and are beneficial in the information and insights they provide on the context in which the research is being conducted in (Bowen, 2009). Once the appropriate data collection methods were selected, an interview guide was created.

\subsubsection{Interview guide}

Once a semi-structured interview method was selected, the literature was reviewed to act as a guide. The information and insights taken from the literature were used to create the interview guide for each of the three levels of the organization with relevant themes and topics to address the research question. These guides are provided in Appendix A. 
In order to conduct a fluent interview, the questions were allocated according to topics. There were a total of four to five parts to the interview depending on the level at which the interviews were conducted at. These include: an introduction, overview questions, questions related to information sharing, questions related to visibility, questions related to collaboration, and concluding questions and statements. Although a full guide was created, along with a section of potential prompts in the case it was needed, the order was not necessarily followed at all times due to the flow of the interview and if any new information piece was added by the participants. For some of the interviews, participants would begin to discuss points that were not part of the original guide, prompting the need for further questions for clarification from the interviewer (investigator). Therefore, the interview guide was used as a tool to ensure the interview followed a structure, while still allowing for new insights and clarification (Cohen \& Crabtree, 2006).

Once the interview guides were created, they were reviewed in order to test the questions to ensure relevant points were addressed. The review of the interview guide resulted in some minor changes including the overall organization of the interview. It was at this stage that potential prompts were added in the guide for the use of the investigator in the case clarification or expansion on a point or question was needed. Also, upon reviewing the questions, a separate data collection form was created to collect information on the participants' place of work and their job title, which are presented in Appendix B. This was done as a form of participant screening to ensure that all the participants interviewed were employed at the same retail organization, and that the participants were employed in one of the three levels that were being studied: strategic, warehouse, and retail. The next section will discuss participant screening and recruitment in further detail. 


\subsubsection{Participant screening and recruitment}

The research was designed to focus on one retail organization at three key different levels. The three levels were selected on the basis of key functions within the organization and included participants at a strategic level, a manager at the warehouse level, and at a manager at retail store level (Juneja, n.d.). These three levels were chosen to gain a deeper understanding of the functions and processes of each level, and to understand the working relation amongst the different levels.

In order to recruit participants for this research, purposive sampling was used. Purposive sample occurs when all possible cases that fit the criteria were used using various methods (Neuman, 2014). Potential participants were approached either in person, or those not accessible in person were contacted through email once an introduction had been made through a connection. In order to ensure consistency in recruitment, a script was created for both recruitment avenues which are provided in Appendix C. A total of sixteen participants were contacted to take part in this study, of which six completed the full interview process. In order to ensure that the findings were not impacted by the participants that opted out of taking part in the study, a variety of methods were used.

The first method was through the use of triangulation. Triangulation refers to using a variety of different approaches to create a better understanding of a given subject (Turner, Cardinal, \& Burton, 2017). For the purpose of this study and to create consistency, triangulation was done by conducting semi-structured interviews, observations at multiple levels, and through the attainment of documents.

As the second method, the provided documents were used to ensure that the findings were not impacted. The documents provided information on the different policies, and processes 
that are used throughout the entire organization. This ensures that the information collected from the participants would not differ or have an impact as the policies and processes remain the same. Finally, as the third method, the collected data is analyzed and checked for consistency throughout all three levels to note any convergences. By utilizing a variety of methods, the principal investigator was able to ensure that the final findings were not impacted by those participants that chose to opt out.

\subsubsection{Collecting the data}

Once participants were recruited and had agreed to take part in the study, they were provided with a copy of the consent form in advance to provide them with sufficient time to review and ask any questions they may have. A copy of the consent form is included in Appendix D. The interviews were all conducted in English with a total of six participants, each taking approximately one hour. The interviews were all voice recorded with their permission for the purpose of transcription and analysis. Each participant was assured of confidentiality, as stated in the contract form and has been assigned pseudonyms and identified using initials throughout the entire study.

In addition to the interviews conducted, observations were made at the retail and warehouse level. The retail observations were conducted at a larger retail store in order to understand the flow of seasonal inventory during peak holidays. The warehouse observation was conducted through an invitation by one of the participants who offered to guide the investigator through one of the main distribution centres which services central Canada, including approximately 140 retail store locations. The guided tour included a walkthrough of key areas in the distribution centre responsible for the handling of incoming and outgoing inventory, and observations regarding areas of concerns were noted. The final method of data collection, as 
mentioned in Section 4.2.1 was through documents that were voluntarily provided by the participants to provide a visual example of the topics discussed.

\subsection{Analysis}

After the interviews were conducted, they were transcribed for analysis. The transcribed interviews along with the observations and documents were organized together based on the level at which the interview were conducted at and the related questions. The selected method of analysis is discussed in the following section.

\subsubsection{Qualitative analysis}

Thematic analysis was selected as the method for analyzing the collected data. Thematic analysis is defined as a "method for identifying, analyzing and reporting patterns (themes) within data" (Braun \& Clarke, 2006, p.79). Thematic analysis is helpful in that it allows the researcher to identify common themes across a set of interviews (DeSantis \& Ugarriza, 2000) to provide a detailed account of the data that were collected. As flexible as qualitative research methods and semi-structured interviews may seem, in order to effectively conduct a thematic analysis it is essential to understand and follow a clear set up guidelines to ensure consistency throughout the

entire process. For the purpose of this research, six crucial steps were adopted from Braun and Clarke's (2006) study on conducting a thematic analysis.

Step 1. Getting familiar with the data that were collected. This is an essential step at is important to know and understand all the data that was collected. For the purpose of the research, the interviews were transcribed and the all the data was organized according to the relevant levels and questions, as described in Section 4.2.4. Once the data has been organized it is recommended to note down any initial ideas that arise from reading and re-reading the data as it 
sets the tone for the formal coding.

Step 2. Generating the initial codes, which means to systematically highlight key features from the data set and organizing the data according to the codes that were generated. This step is essential as it aids in creating a larger umbrella for future themes that will be generated from the data set.

Steps $3 \&$ 4. Searching for and reviewing the themes that were generated from the coding umbrella. This phase in the analysis process is one that requires constant checking to ensure all the data is relevant to the themes and to the if they work in relation to the codes described in step 2.

Steps 5 \& 6. Entailing the reviewing, defining, and naming of the themes, along with the production of the final report. Step five is essential as it is one in which the themes are defined and the relevant data collected from the data set are used as examples. It is essential to follow a clear set of guidelines throughout the analysis process to ensure there is consistency in order to generate narrative that has both merit and validity.

\subsubsection{Coding and analysis}

Once a clear set of guidelines were established, as described in Section 4.3.1, the steps were followed for the purpose of this research and will be further described in detail. For this research a manual method was used to analyze the data. This is because of the small data set and unique research design in that three different data sets were analyzed due to the three different levels and two interviews conducted at each level.

After the data sets were organized, the first approach was to clearly understand the data and make note of specific examples and common themes. This was done through a manual process in which the researcher thoroughly went through the data set and physically highlighted 
the initial key findings. The content of the data sets were organized using a colour scheme from which quotes, and findings were later taken to establish themes for the final narrative. Throughout the coding process it was important to review and re-review the highlighted themes to ensure a proper fit between the identified themes and examples. This is a necessary step to reduce the risk of missing any key examples, or to ensure examples are not used under unrelated themes.

Once the initial codings were completed by the principal investigator, two additional coders were recruited to complete an inter-reliability test to ensure there is a degree of agreement in regards to the themes and codes. The coders were chosen based on their experience and familiarity with the coding and analysis process. Each coder was provided with the same set of approximately 40 percent of the transcripts and instructions on how to carry out the analysis. Once the coders were each given the opportunity to pick the most critical concepts, the principal investigator and coders convened to discuss the results until a 90 percent was achieved, which according to McHugh (2012) is considered very strong. The final narrative was written based on the results of these findings. 


\subsubsection{Reliability and validity}

For the purpose of this study, steps were taken to ensure the research has both validity and reliability. This was mainly done by triangulation (Figure 1), which is advocated as a way to strengthen any study by combining different methods (Golafshani, 2003; Leung, 2015). The use of multiple methods aids in ensuring there is convergence in the data that is collected. For this research, this was done by conducting interviews with more than one person for each level to note a merging in their responses.

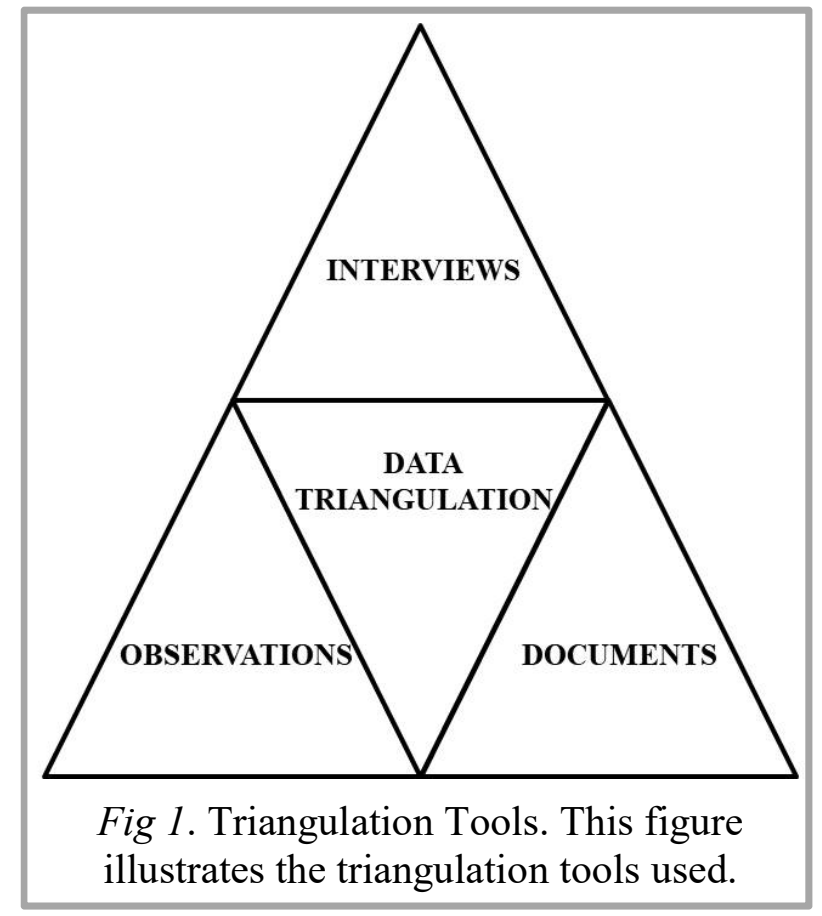

Observations were also used as a way to increase validity. Observations help in better understanding the situation which is being studied (Kawulich, 2005). In this research, the use of observations in conjunction with the interviews strengthened the findings in that similarities were noted. A final tool used to increase validity was through the use of documents provided by the participants. The documents, as described in Section 4.2.1, were used as a tool to enhance the discussions which occurred during the interviews.

In addition to validity, it is also important to ensure the research reliability. For the 
purpose of this study, an inter-rater reliability analysis was conducted. An inter-rater reliability refers to the consistency of decisions that are made by two or more raters (Lavrakas, 2008). Once the investigator completed her initial coding, two additional coders were selected to complete a similar analysis on approximately 40 percent of the data set. The coders were asked to sign a coder confidentiality form, as seen in Appendix E, to ensure proper protocols were followed and to uphold participant confidentiality. Once the coders completed the coding of their data set, in order to reach an agreement on the findings, the principal investigator and coders convened until they reached a 90 percent consensus. 


\subsection{Results and Discussions}

This chapter will present findings from the data collected. The aim of this research is to gain a deeper understanding of strategies being practiced by a retailer to improve performances for the handling of their excess seasonal inventory. First, the characteristics of each participant that took part in the study will be presented. Followed by a section that will provide a breakdown of the findings and present a discussion for each strategy at the three levels at which the interviews were conducted. The findings will be discussed in relation to both the outcomes of the data collection methods, as well as the literature in order to make connections.

\subsection{Participant Characteristics}

A total of sixteen participants were contacted to take part in this study, of which six completed the full interview process. There were two participants for each of the three categories that were being looked at for the purpose of this case study. The participants at the strategic level are both from the retail organizations main head office, the two participants at the warehouse level are from two different distribution centres each of which are responsible for different types of inventory, and finally, the two participants at the retail level are in managerial positions at two separate brick-and-mortar locations. Table 3 provides a summary of the names (initials), area in which the participants work, as well as the position title for each of the six participants. Each participant will be referred to by their initials in subsequent sections.

Table 3.
Participant Characteristics
\begin{tabular}{|cccc|}
\hline$\#$ & Initials & Area & Position Title \\
1 & TP & Strategic & Assistant General Manager \\
2 & GC & Strategic & National Manager \\
3 & CS & Warehouse & Operations Manager \\
4 & JG & Warehouse & Operations Manager \\
5 & ZO & Retail & Store Manager \\
6 & YB & Retail & Store Manager \\
\hline
\end{tabular}




\subsection{Discussion}

For the purpose of this research, three levels were selected on the basis of key functions within the organization and included participants at a strategic level, warehouse level, and at a retail store level (Juneja, n.d.). Figure 2 provides a visual on the connections made throughout the data collection process. Participants at each level were asked questions specific to the three strategies being explored in this research. The key findings and discussion for the strategic level will be presented first, followed by the warehouse level in Section 5.2.2 and the retail level in Section 5.2.3.

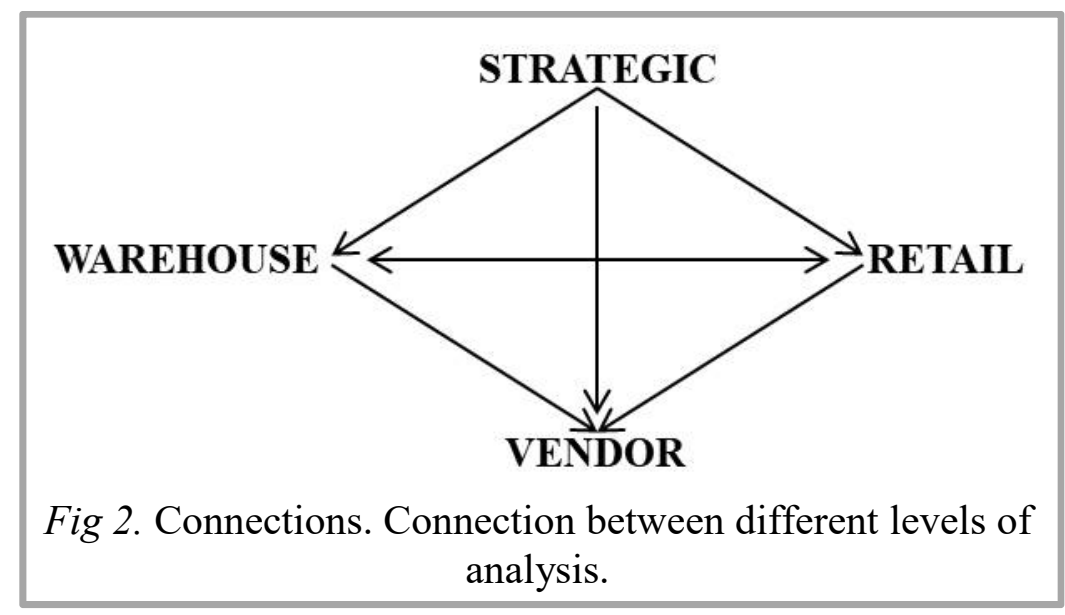

\subsubsection{Strategic level}

The strategic level is one at which an organization defines its strategies or direction and plans accordingly to follow the strategies and those at this level tend to focus on three main questions; what, for who, and how (Oboni \& Oboni, 2014) when it comes to creating their strategies. The participants at the strategic level, TP and GC were asked about the policies or strategies in place to manage seasonal inventory in order to get a wider understanding of company practices, to which they both stated that there isn't a policy in place, it is "more of a strategy $[. .$.$] we have to actually handle the inventory" (GC, 2018).$ 
Based on the responses, it is apparent that the organization does not have specific policies in place to manage their seasonal inventory, rather they have steps they follow to handle the inventory. Both participants stated that the analysts "calculate the cost of holding the items in inventory and once either they come across an item that's been in holding for a while, or it's becoming to cost more than was anticipated [it is then] addressed and dealt with" (TP, 2018). They are essentially trying to calculate "how long the inventory can be stored on the shelves before it starts to become a liability" (GC, 2018). Once it has been determined the inventory is older and the excess needs to be dealt with, the organization needs to "find a way to process it. [...] it's generally sent to a third-party retailer" (TP, 2018).

There is a convergence in the responses from both participants at the strategic level. The handling of excess seasonal inventory is based on calculations done by analysts who are constantly monitoring the inventory within their category. There is a calculation in place to assess the life of an item on the distribution centres shelves before it becomes a liability. Once it has been determined that the items on the shelves will not provide any benefits, the organization generally cycles out the merchandise through the use of a third-party retailer. When referring to excess seasonal inventory and the way in which it is handled, the strategic level participants directed their responses from the first-touch level, the warehouse or distribution centre. The handling processes for the other two levels will be discussed in subsequent sections.

\subsubsection{Discussion on information sharing}

One of the first strategies that was looked at for this research was information sharing. To better understand the organizations procedures regarding information sharing, the participants were asked about the existence of policies or practices in place. The question was directed towards any general policies or practices, as well as those between different partners in the 
organization such as vendors and distribution centres, vendors and retail stores, and retail stores and distribution centres. The participants stated that there is "an integrated supply chain with the replenishment teams and the vendors' inventory" (TP, 2018) and "the replenishment and vendor teams work together so they have access to each other's information [...] it's an integrated system" (GC, 2018).

The objective of asking questions regarding policies and practices was to gain an understanding of the way in which the strategic level of the organization makes decisions and to understand the policies and practices that are expected to be followed by the other levels. The retail organization that was the subject of this case study has both a clear policy on information sharing as well as practices. In the process of the interview, the importance of an initial nondisclosure agreement was noted due to the sensitivity of the information that was being shared with the different levels. It was explained that once proper contracts have been signed, the parties become a part of an integrated system that works together to ensure that "needed information is being shared when needed" (GC, 2018) and in the case of the studied retail organization, it was mainly through the use of an online login system that gave parties the relevant information they may need.

In addition to having certain information sharing policies and practices in place, it was important to note the different types of information that is shared amongst the various partners from the strategic level. GC highlighted the more prominent pieces of information shared including "sales information, inventory in store, pricing information, it's a detailed breakdown of everything. How many PO's [purchase orders] are in pending, what we are expecting on the floor [...]. All that information is available. Anything you can possibly imagine.” (GC, 2018).

One of the participants mentioned five pieces of information that is shared with different 
parties, a few of which coincided with what was observed in the literature (that was summarized in Table 2). The first one stated by the participant was sales information, which according to Lumsden and Mirzabeiki (2008) can help with better decision making in regards to inventory and can also allow for better planning in regards to future production.

Another piece of information was sharing of inventory levels, or knowing one's own inventory. According to the literature, this piece of information adds value for multiple partners in an organization in addition to the final customer. This is noted to be important for customers so they are more aware of their choices and shop accordingly. For retailers, this piece of information is essential at is important to be cognizant of the products that are available for sale in order to generate sales, this will also be further discussed from the retailers perspective in Section 5.2.3. Familiarity with inventory levels can also allow for more accurate inventory control and improve order processing times, as well as schedule shipments accordingly (Lumsden \& Mirzabeiki, 2008).

In addition to the benefits noted in the literature for sharing information amongst various partners in an organization, the two participants also stated that by having a policy or practice in place, and by sharing information, they are "better [able to] plan and respond to changes" (GC, 2018) and it gives the team the "agility and speed to respond to any fluctuations" (TP, 2018).

\subsubsection{Discussion on visibility}

The focus for this strategy was the different tools used by the organization to increase visibility as well as the benefits they noted by utilizing these tools. It was deemed important to gain an understanding of the different tools used by the organization to increase visibility. The participants mentioned a total of four tools: (1) RFID, (2) POS system, (3) a company created online system, and (4) ERP's. The tools used either cooperatively or on their own, provided 
benefits such as "the ability to forecast and do the trend analyses" (TP, 2018) and "help[ed] everyone be on the same page for everything. [They] can forecast better throughout all areas of the business, like retail stores, and DC level. All of these help [them] do the analyses' too so teams aren't over buying and everyone is working together." (GC, 2018).

Forecasting in general is a challenging task for many retail organizations due to the vast complexities and factors that imminently play a role. As competition has become more stringent, many retailers have turned to improving their forecasting methods to achieve a goal of reduced costs and increased profits (Aye, Balcilar, Gupta, \& Majumdar, 2015). Based on a study done by Zhang (2009) on retail sales forecasting, accurate forecasts can help improve a retail organizations supply chain operations and performances. Both participants from this study stated that better forecasting is a direct benefit from the use of these visibility tools.

One of the benefits mentioned by a participant was that the of these visibility tools "help[s] everyone be on the same page for everything [...] so teams aren't over buying and everyone is working together." (GC, 2018). This is similar to what was found in a study by Christopher and Lee (2004), in which they stated that end-to-end visibility would increase confidence amongst supply chain managers. The increase in confidence arises from all the partners within the supply chain having clear visibility in all the necessary areas. An example to depict the severity of limited visibility in a supply chain was provided in a study by Christopher and Lee (2004). In this example, the sales team believed the fulfillment times to be unreliable so they developed a plan to address the issue on their own by ordering additional safety stock. The lack of visibility for the sales team resulted in the organization owning more stock than was needed which would generate higher inventory carrying costs. The use of the visibility tools at this organization would be a counter measure against the outcome mentioned in the example. 


\subsubsection{Discussion on collaboration}

The third and final strategy that was explored at the strategic level is collaboration. Collaboration can occur amongst many different levels of an organization, each with its own benefits. For the purpose of this research and to gain a wider picture of the practices of the organization, a focus was made on the connection between the vendors and the strategic level.

Based on the responses of the participants, it was noted that the organization does utilize collaboration by working closely with the "vendors supply chain analysts, $[\ldots]$ buyers, $[\ldots]$ our [the organization studied] replen[ishment] team, and the vendors team" (TP, 2018). In order to effectively collaborate, the organization has tools available for the teams to work closely together. These tools include: CPFR, which is collaborative planning, forecasting, and replenishment, ECR which is efficient consumer response, and VMI, which is a vendor-managed inventory system. The second participant mentioned the login system that is used across the organization and refers to the VMI method. Each of these methods serves a specific purpose but they also equally enable the organization to work with various partners to reduce costs of excess inventory (Seifert, 2003; Cho \& Lee, 2013).

In addition to working together, it was worth noting the characteristics the retail organization looks for when choosing partners to collaborate with. According to GC, the organization uses a scorecard with which they score potential vendors. Vendors are required to meet a certain level for six different categories including: cost, delivery and support, compliance, flexibility, quality, and innovation. Furthermore, according to the supporting documents provided, the organization conducts frequent reviews to monitor the performances of the vendors they collaborate with. The review is based off of the six main key performance areas mentioned previously. However for the purpose of conducting the review, each of the key areas have 
additional associated performance indicators. The indictors are given a different weight which is assigned by importance. The reviews are conducted to ensure the vendors collaborating with the organization are able to maintain their performances as to not adversely affect the organization. An interesting point mentioned by the participant in regards to the metrics was that there is an emphasis on the sales generated by a vendor. "If a vendor has been assigned a specific task or target [...] and they don't reach [the target] they have been assigned, [or are unable to] touch [the target] line throughout the year, we will take that product off for the next year" (GC, 2018).

In interviewing the participants regarding the benefits of collaborating, they point out “there's a relationship being formed. The teams work together to ensure things are done right. Again, it's a cycle; share the information, which goes hand in hand with providing visibility, then working together to get the right products on the shelf at the right time." (GC, 2018). This is also consistent with the literature where collaboration between different levels of an organization can help strengthen the supply chain (Daugherty et al., 2006). Partners work together towards a shared goal to make sure things are done correctly and as it a retail organization that deals with physical inventory, to ensure the right products are on the shelf at the right time. An overview on how seasonal freight is processed, and moved will be further discussed in subsequent sections.

\subsubsection{Warehouse level}

Due to an increase in competition, globalization, and continuous changes in customer needs, organizations continue to modify their operations to improve their overall performances (Laosirihongthong, Adebanjo, Samaranayake, Subramanian, \& Boon-itt, 2018). Warehouse operations play a significant role in achieving a higher performance through the use of various methods (Nair, 2005). For the purpose of this study, the uses of the three strategies at the 
warehouse level are considered. The participants at the warehouse level, CS and GC were asked about how often they have to address excess seasonal inventory in order to get an understanding of the adherence and link of the strategies set in place at the strategic level.

Similar to what was stated by the strategic level participants that there is a calculation done in order to assess whether items need to be moved off of the distribution centre shelves, the warehouse level stated "there's no set number of times [they] deal with excess. It's what and when [they are] told to process based on calculations the team have done" (CS, 2018). The second warehouse level participant also stated that they deal with excess seasonal inventory "usually whenever [they are] told to address certain inventory by head office" (GC, 2018).

The second participant also stated they sometimes find themselves with limited shelve space, so they send in a request to the team at head office to move older freight off of the shelves to make space. This point was corroborated by observations made at the warehouse level at which it was noted that there was limited space to accommodate for newer merchandise coming in due to older freight already allocated to the shelves, such as older Christmas trees. Due to this, the warehouse manager stated they sometimes have to request for options to address the freight earlier as the distribution centre is dealing with inventory coming in from multiple areas such as vendor shipments and store returns.

In addition to observing and inquiring on the frequency and the way in which excess seasonal inventory is dealt with, the two participants were asked of key performance indicators to monitor the inventory. Both participants stated that the most important key performance metric they have in place is "cases per hour" $(\mathrm{CPH})$ as it "shows how many cases are actually going out of the DC and are being processed" (CS, 2018). CPH was also mentioned to be one of the most important metrics as it helps the warehouse team set their own forecasts based on the 
assigned goals by head office to reach budgets. This also gives them another way to keep track of current volumes as $\mathrm{CPH}$ "takes in to consideration all the various receiving forms at the DC" (JG, 2018). Performance measures are critical for companies to improve the effectiveness and efficiencies of their supply chain (Cai, Liu, Xiao, \& Liu, 2009).

As explained by CS, the way in which the freight is received at the warehouse depends on the type of freight. There are two departments that process incoming freight, of which the first is Distribution Assembly which handles all of the conveyable and mixed trailer loads. Conveyable items are labeled and placed directly on the conveyor system which leads to specific store trailers in the shipping department. Mixed trailer loads consist of freight that needs to be sent to smaller departments for processing or short-term storing before it is shipped out. The second department for processing incoming freight is Staple Stock. This department manages larger, bulkier items such as patio or barbeque sets that are stored on the warehouse shelves until it is needed by the stores. In addition to cases per hour, the warehouse also monitors inventory by four other metrics including: inventory turnover, inventory or cycle count accuracy, cost of carrying inventory, and damages.

\subsubsection{Discussion on information sharing}

Following a similar order, the first considered strategy is information sharing in order to better understand how the strategy helps improve performances. The participants were asked a set of seven questions, each focusing on a specific piece of information that was observed in the literature, see Table 2. The participants rate the importance of each piece of information, whether the information was shared, and the observed benefits. The seven pieces of information are: location of the product, condition of the product while in shipment, position and sequence of the products, own inventory levels, lead time, shipping quantity, and retail sales history (Zhang et 
el., 2006; Lumsden and Mirzabeiki, 2008).

Of the seven pieces of information four were agreed upon as vital by both participants and included the condition of the product while in shipment, their own inventory levels, lead time, and shipping quantity information. According to Lumsden and Mirzabeiki (2008), the condition of the product while in shipment is important for various supply chain partners as different products may have different requirements and it is also important to have in order to hold each of the partners accountable in the case of a fault. Interestingly, the organization under investigation has a non-compliance policy in place that is imposed on vendors to ensure products are sent meeting the specific requirements to "avoid retouching the product too many times" (CS, 2018) as according to observations, having to rework items can waste time and resources. However, despite having a strict policy, the organization is "currently [...] making, or charging [vendors] almost $\$ 20$ million a year" (CS, 2018) because of products not sent correctly, or damaged.

The second piece of information stated to be vital is having knowledge of one's own inventory levels as without this knowledge, it would be very difficult to plan. According to CS, this information also informs the teams of the minimum threshold that should be maintained, the cycle of the products, and notifies the team of when the assets start to become a liability. In having knowledge of inventory levels, managers are able to make more informed decisions as it moderates any unpredictability, which therefore increases the chances of reduced inventory levels (Zhang et al., 2011).

The third and fourth pieces of vital information are lead time and shipping quantity which are both readily available through a manifest which provides a variety of information such as "vendor name, the type of freight, the quantity, [and] the time [they] should expect the load" 
(CS, 2018). According to Bowersox et al. (2007) having this information shared adds value and allows for more efficiencies between partners and also allow them more time to resolve and adapt to uncertainties (Zhang et al., 2006).

In addition to the value of each piece of information found in the literature, there was an agreement by the participants on the benefits provided by each. These benefits included increased efficiencies in processing freight. This results in a higher $\mathrm{CPH}$ rate and the shared information allows for the effective planning of all resources such as the proper scheduling of "team members with specific skills" (JG, 2018). CS succinctly stated the connection between all the benefits as "better planning of manpower, [means] more items getting processed, mean[s] higher cases per hours, meaning higher turnovers".

Now, an important point made in relation to knowing the inventory levels and understanding the calculated threshold was the reason as to why some seasonal items may be kept on the shelves for a little longer. JG (2018) stated that in the case of many seasonal items, such as barbeques, not a lot of technological changes occur in the succeeding versions, which is why when calculating the cost of holding versus selling, organizations are able to carry it over for a longer period. In comparison, if the buying team were to place an order for two years' worth of iPads due to a discounted deal, it would be considered a mistake. It would be highly unlikely that the company would be able to sell the entire inventory before a newer version or model is introduced in to the market, making the current inventory nearly useless. Therefore when it comes to seasonal inventory, such as barbeques or patio sets, the company has a higher chance of keeping it on the shelves. There is still a chance of it selling in the next season as the threshold is calculated to be a little longer for seasonal items. This will also be discussed from the retail's perspective to gain a deeper understanding. 


\subsubsection{Discussion on visibility}

Similar to the previous level, the focus for this strategy was the different tools used by the organization and the benefits they noted by using these tools. At the warehouse level, the participants mentioned three main tools: an internal system, TPR, and a live system.

The company's internal system allows users to access a variety of information related to their respective departments and needs such as: the description of an item, the costs of an item, warehouse stock levels, and shelf availability. The TPR, which refers to the planning or performance report is a daily tool used by management to keep track of the "hours used, how many people were working, all this information to factor in and calculate to see if [they are] reaching [their] goals. This shows [them] the PI's, performance indicators for each department" (CS, 2018). The final tool is a live system which is visible on various monitors throughout the

warehouse "that shows the full conveyor system, and in case anything goes wrong, or something gets stuck they can see right away where the problem is. [... It] shows all the freight that's being sent on the conveyor system [which also] helps [...] look at shift productivity" (JG, 2018).

In discussing the various tools used by the organization at the warehouse level, the participants stated that in using these tools, they can reduce any abrupt planning which forces them to overuse resources. The tools allow the teams to be more cognizant of what is happening across different areas, what inventory is coming and going through the system, and which areas may need improvements. The combination of the tools mentioned by the participants also "gives [them] an advantage and can really help [...] make sure [they are] on top of things" (JG, 2018) which translates in to a higher cases per hour rate, faster receiving times, and processing times. This observation is also aligned with the literature where an increase in visibility was noted to result in improving overall supply chain performances (e.g., Mwencha and Rosen, 2016). The 
increase in visibility also lowers costs however this needs to be done in conjunction with striving for continuous improvements as was similarly stated by both participants at the warehouse level.

\subsubsection{Discussion on collaboration}

Examples of the confidence in the vendors' actions were mentioned throughout the interviews by both participants in regards to the completion of contracted tasks and information shared by the vendors. CS mentioned that it is fundamentally up to the vendor to ensure the freight is coming in according to the company's policies and on schedule. This was a point similarly made by JG in which as long as the vendors are fulfilling their obligations, there is no need to concern themselves with the Vendor's internal operations. These points were brought up by the participants when they were asked about the importance of knowing the position of the vendors' inventory at their distribution centre. This is similar to what was found in the literature in which an important aspect of collaboration is having a trusting relationship between the supply chain partners where there is confidence in the capabilities and actions of each member (Sahay, 2003). The examples stated by the participants portray that there is trust and confidence that has been built between the company and an external partner.

Comparable examples were made about the confidence in the vendor's actions about having lead time and shipping quantity information shared. The participants stated that such information is expected when scheduling the delivery of freight from a vendors distribution centre to the company's distribution centre. This information is used to help plan the company's resources accordingly. This information is also used as a form of contract between the two partners to ensure the vendors are sending the correct freight, or that the correct freight is received by the company's warehouse team.

A point discussed by CS in regards to the advance planning of seasonal merchandise such 
as Halloween was that it is not necessary that all "vendors make each item, so [they] need to make sure and work in advance to capture the sales before other competitors". It has been also stated that seasonal times are crucial so advance planning is important to ensure the items can be received at the retail level, and end customers in time. This was a point similarly noted in the literature that in addition to the confidence in the capabilities and actions of the partners, it is important to work together. This is to happen in conjunction with creating a focus on the customers by integrating all the different processes and factors in order to meet business objectives so organizations are able to make more strategic and reliable decisions in regards to inventory (Choi et al., 2008).

\subsubsection{Retail level}

A retail brick-and-mortar store is an area in which meaningful and direct relationships are made with customers as the organization has the ability to create visible engagement between the consumers and their available products (Trotter, 2016). The physical store is one of the main distribution avenues for the retail organization and is an essential source of competitive advantage (Turley \& Chebat, 2002). For the purpose of this study, the uses of the three strategies at the retail level were considered.

The participants at the retail level, $\mathrm{ZO}$ and $\mathrm{YB}$ were asked what key performance indicators they have in place to monitor the inventory, these measures are critical to have in place for companies to improve the effectiveness and efficiencies of their supply chain (Cai et

al., 2009). Both participants stated there are six main measures to monitor their inventory, of which one acts as an umbrella measure. These measures include: inventory turnover, replenishment, returns, damages, sales, and BIR which is a "bin reporting inventory system from 
a KPI perspective that measures the amount of productive and non-productive inventory" (YB, 2018). According to ZO, productive inventory is inventory currently available on the floor and is for sale, whereas non-productive inventory is classified as inventory stored in the retail locations backroom which is carried over to future seasons.

The discussion on performance measures lead to a conversation on how the store addresses excess seasonal inventory at the retail level, to which both participants responded with similar answers. Seasonal inventory is addressed on a constant basis due to the availability of space and store managers have different avenues available to them to address the excess inventory including: condensing the seasonal merchandise, carrying some of the inventory, try to liquidate the items by doing price markdowns, or by processing return authorizations.

Condensing the seasonal merchandise means moving the seasonal item in to a regular planogram or, in the case of some locations, they may carry a smaller seasonal section year long. For example according to YB, "some stores carry a smaller garden centre, like an indoor garden centre throughout the year, [... so they will] reduce the area of the full blown garden centre to maybe one-tenth of the original size to carry things like barbeque all year long”. In choosing to carryover or liquidate, it all depends on the item. There are calculations done in which it may be better for the store to carry the item over until the next season as they may not "want to blow it out at a ridiculous price and liquidate it, it's a waste of GP [gross profit] dollars" (YB, 2018).

In many instances, a decision may be made on carrying over the item but "to avoid filling the backroom shelves with old seasonal merch[andise], or just old merch[andise] head office [...has given] the option to process returns authorizations" (ZO, 2018) which allows the retail store to send merchandise back to either the distribution centre, or vendors. The processing of return authorizations was observed from the warehouse level perspective when the warehouse 
managers stated they sometimes have limited space to accommodate for newer merchandise due to older freight already allocated to the shelves, and because they are dealing with inventory coming in from multiple areas such as vendor shipments and store returns. This point will be further discussed in Section 5.2.4.

\subsubsection{Discussion on information sharing}

To gain a better understanding on the use of information sharing at the retail level, the participants were asked what pieces of information were shared with them. Both responded that they receive various pieces of information from three main sources such as: head office, distribution centres, and direct-ship vendors. From head office the store level receives "merchandising directives, planograms, information and directives on the seasonal or community events, budgetary information, [and] forecasting info" (ZO, 2018). Interestingly, it was stated that the directives, planograms and events are planned according to the demographics of the stores customers which is consistent with the literature in which retailers have realized the importance of differentiating their offerings due to a rise in the emphasis on customer experience (Deshwal, 2016). From the distribution centre, they receive "logistics and carrier info[rmation ...] when the next truckload is coming in, $[\ldots$ they] get an invoice from the DC which has $[\ldots]$ all the information [they] need in relation to the load. So item, quantity, like the exact items description" (ZO, 2018). From the direst-ship vendors, the retail store will receive information similar to what is received from the distribution centre.

Similar to the warehouse level, the retail participants were asked a set of six questions, each focusing on a specific piece of information that was observed in the literature to benefit partners in the supply chain. The participants rate the importance of each piece of information, whether the information was shared, and the benefits they observe from having the information. 
Of the six, the participants considered three pieces to be vital, including having knowledge on their own inventory levels, receiving times, and shipping quantity information which were also ones mentioned by Lumsden \& Mirzabeiki (2008).

In observing all the different pieces of information that is shared, it was also important to understand the benefits the participants noted from having each piece of information shared with them. These are in addition to the benefits noted in the literature for sharing information amongst various partners in an organization that were discussed in previous sections of this chapter. There were commonalities in the responses from both participants throughout; as they stated that having the information helps plan their resources and floor plans. For example, YB stated that if they were not "told of the upcoming events, like Halloween, or Christmas, or the next major one Valentines, $[\ldots$ and they were unaware] of the plans they have set out for Chinese New Year, [they] could potentially still have barbeques in the areas where [they] need to set up the ethnic event, or [they] won't have space". In knowing this information in advance, the store managers have the ability to process return authorizations which will help clear both floor and backroom space for newer merchandise.

In addition, ZO stated that in "process[ing] returns to the DC, [they] won't have a high NPI [non-productive inventory]. [... In regards to] PI [productive inventory], if [they are] able to push the newer merch[andise] on to the sales floor right away, it's all PI, [they] should be seeing an increase in sales, $[\ldots]$ cycling out inventory then. Getting quick replen[ishments]."

YB stated that sharing information results in "smooth inventory turnover and controlled in-stock inventory". This was similarly stated in a study by Cho and Lee (2013) in which they found that an increase in information sharing results in a decrease in excess inventory specifically during seasonal occurrences. 


\subsubsection{Discussion on visibility}

Taking into consideration the benefits of visibility on a supply chains performance, it was important to understand the different tools the organization uses to increase visibility at the retail level. The participants mentioned a total of four tools: the POS system, a company created online system, and two additional company created systems. The tools used either on their own or jointly, provided multiple benefits such as generating better forecasts, planning future return authorizations, monitor sales, conduct analyses, and be able to adjust according to needs. To further understand the tools, their benefits, and how they improve performances, the participants' statements as well as key findings mentioned in the literature are considered.

The POS systems created less pressure for the retail management team according to ZO as "all basic stock [...] relies on getting [replenished] off of the POS transactions. [For example...] if a customer buys a lipstick, then it'll go in to the system and an automatic [order will] get placed". Also, as previously mentioned, forecasting plays an important role for a retail organization (Xiao \& Qi, 2008) and many retailers have created a focus on improving their forecasting methods to achieve a goal of reduced costs and increased profits (Aye et al., 2015). This is also one of the key benefits noted from the use of the POS systems.

The use of these tools also provided "visibility to a lot of information. [Such as] sales, [...] keep track of inventory" (ZO, 2018) which are used by various partners such as the retail stores, suppliers or vendors, and head office for the purpose of planning. Similarly, the retail level is able to use a tool from which they have the ability to access information sent along from the vendor to the warehouse, to the retail level. With this tool the store managers can see "seven days out in terms of what trailers are in the pipe [... which gives them] enough time to plan the fulfillment teams and for leads to get the manpower together" (YB, 2018). This is consistent with 
what is reported by Bartlett et al. (2007) in which visibility can be achieved by various partners working together.

\subsubsection{Discussion on collaboration}

For this study, all participants were provided with definitions for each strategy in order to ensure that the responses were all under the same context. When questioned on the importance of receiving certain pieces of information, YB stated that 'everything's linked together. It's a collaborative effort to reach and exceed the KPI's we've got in place" which falls completely in line with the definition used for this strategy. The definition provided for this strategy was that collaboration within a supply chain environment occurs when two or more independent companies work together to jointly achieve greater success than what can be achieved by just working alone (Daugherty et al., 2006).

Likewise, in discussing the benefits noted from sharing information, $\mathrm{ZO}$ stated that it is not just a single factor that would result in a single outcome, but rather if multiple factors or events happen it would result in that single outcome. Therefore, it is in working together at multiple different levels that can provide wider benefits.

A final example of collaboration noted at the retail level is in reference to the visibility tools utilized by the retail store managers to make collaborative changes to merchandise coming in. According to YB (2018), the tool allows the store managers to work with the replenishment

division who work with vendors to come to an agreement on a potential increase on the flow of perpetual inventory, instead of the managers just overriding the system and placing manual orders. Consistent with the literature, this reduces any variances involved in individual decision making as collaboration is a strategy to reduce certain risks (Cachon, 2004; Heckmann et al, 2015; Sari, 2015). 


\subsubsection{Important Factors}

In the process of conducting the interviews, additional factors were identified that could impact the outcome of the discussed strategies. These factors include: (1) human errors, (2) communication gaps, and (3) the failure to see the effects a decision has on other internal partners.

\subsubsection{Discussion on human errors}

A common point mentioned throughout all three levels was the potential for human errors. In discussing the use of visibility tools and collaboration at the strategic level, GC (2018) mentioned that human errors affect the team. However, through the availability of the tools and in using them properly, the inventory should be streamlined.

Examples of human errors and its effect on inventory levels was mentioned at the warehouse level as well in which CS provided an example that sometimes mistakes are made when team members reorder inventory without realizing what is already in stock or has been ordered. For example, if there are already 500 pieces in stock of an item and they need a total of 1000, sometimes the team members will overlook what has been ordered already and process an additional 500 pieces. However, one of the team members has already processed 400 pieces. Therefore, they now have a total of 1400 pieces instead of the 1000 required. Similarly, the retail manager YB stated that “as long as [they] don't go ahead and do manual overrides, or too much manual ordering, then [they] know the stock [they have...] coming in won't be crazy excessive". Human errors can occur due to a variety of reasons such as a team members working environment (Village, Salustri, \& Neumann, 2016), and the availability of tools (Dewa, Pujawan, \& Vanany, 2017) and affect the supply chain performance, so in improving inventory practices, this would enable better time efficiencies thus reducing costs (Bowersox et al., 2007). 
In discussing the human errors, it was made clear that this was an issue currently faced by the organization and is a mainly a matter of enforcing the proper use of the resources provided. The misuse and errors made can often times result in the organization to carry an excessive amount of inventory which can result in a decrease in revenue, an increase in costs, and an overall reduction in profitability (Hendricks \& Singhal, 2009).

\subsubsection{Discussion on communication gaps}

A second point mentioned from both the perspectives at both warehouse and retail levels are the gaps in communication. Both levels directed their comments towards the head office and strategic level. The "biggest [issue] so far is between the planning team and headquarters to the DC's. That they cannot provide advanced forecast for the DC's to work on. Maximum availability of forecasts is two-three weeks for the inbound freight. They cannot provide for example, that next month on that day, [that they] should expect this much volume or label drops. So there's a communication gap" (CS, 2018). The retail level participant YB had likewise stated "do I wish we had more visibility to what's coming in? Especially during our busy seasons? Absolutely."

In discussing the gap and the affect it has on their operations, CS stated that this effects seasonal inventory more than basic inventory as those are fixed, such as, groceries. However,

for seasonal items, if they did not prepare in advance and are bringing in seasonal items like patio sets in June, it would only leave the retail store approximately two months to sell. However, if they were to begin their planning in advance, around February or March, they will have more months to plan out the seasonal layout. It is important to plan as far in advance in possible so the inventory is available in stores on time. As discussed earlier, and in the literature, sharing information has been considered to be a useful strategy for improving a supply chains 
performance (Huang et al., 2003) and in this case, more timely or advanced information does have an effect on the organizations inventory and the way in which they plan.

\subsubsection{Discussion on the effects of decisions on internal partners}

The third factor was noted from the perspective of the warehouse level based off of the decisions made at the retail level. The retail level, "really [relies] on RA's [return authorizations] to sort of move the products back to the DC in order to create more space at the store" (YB, 2018), however in observing the warehouse operation, it was noted that the warehouses are dealing with an influx of vendor shipments, customer returns, and store returns and encounter issues due to limited shelve space. Due to this, the distribution centre has to request a decision to be made on moving older inventory in order to create space for newer incoming merchandise. This is because they are unable to accommodate higher pallets sent by vendors due to the shelf already being in use. This results in higher packed pallets being positioned on available floor space within the department as they "avoid retouching the product too many times" (CS, 2018) due to the extra resources breaking down the pallets utilizes.

It was interesting to note the emphasis and importance the retail level places on the use of return authorizations in order to clear their own shelves and backroom, without realizing or acknowledging the affect their decision has on their internal partners, the warehouse. 


\subsection{Conclusions, Limitations, and Future Research Avenues}

This section concludes this research study by summarizing the discussed findings, pointing out the research limitations, and discussing some promising research directions.

\subsection{Conclusions}

Based on the completion of the study, the use of the three strategies being practiced by a multi-national retailer were identified to help improve performances in the handling of their excess seasonal inventory in a variety of ways.

This study was designed to focus on one retail organization at three key different levels which were selected on the basis of key functions within the organization. These levels included participants at a strategic level, warehouse level, and the retail level. These three levels were chosen to gain a deeper understanding of the functions and processes of each level. The interviews at the three levels were also used to check the validity of the data collected to ensure there is a merging in the participants' responses. In this study, relevant literature were also reviewed on a variety of strategies currently in practice by organizations to streamline their practices and improve performances. Based on the review conducted, three strategies were identified to be discussed most frequently however; very few of the studies touch upon the role of excess seasonal inventory within a retail context. This study fills the gap in the existing literature by examining which strategies and to which extent they are used by the retail organization to improve performances by the handling of their excess seasonal inventory.

For the purpose of this study, in applying a qualitative, explorative method, six semistructured interviews were conducted, along with the collection of documents in conjunction with personal observations. Two interviews were conducted at each of the levels, with observations done at the retail and warehouse level. The uses of multiple methods to collect data 
aided in ensuring there was a convergence in the findings and helped strengthen the study. Upon completion of the interviews, they were transcribed, structured with the documents and observations, and analyzed through a thematic analysis.

In addition to the main findings of this study which will be summarized later, it is important to note that some findings are either not supported or not identified by the literature. There are three outcomes: (1) some pieces of shared information, (2) communication gaps, and (3) the failure to see the effects a decision has on other internal partners. In regards to pieces of shared information, the literature made note of seven key pieces of information that are helpful for both the retail and warehouse level. However, during the interview process, two pieces including: position and sequence of products in inventory, and location of the product, were commonly found to be not helpful. This is information that is either not shared at the two levels, or was considered to be not helpful as participants stated the teams have their assigned roles and this would be unnecessary information.

Upon completion of the interviews and observations there were common factors reported by multiple participants across different levels. Two of these factors were not pointed out by the literature but were considered important due to the potential impact they could have on the outcome of the strategies. Communication gaps were mentioned at both the warehouse and retail level and were directed towards the strategic level. The gap is mentioned to impact seasonal inventory more than basic inventory as seasonal requires advance planning.

The second factor, which has been not discussed in the literature, is the failure to see the effects a decision has on other internal partners. This was from the warehouse perspective and referred to the influx of inventory the DC is required to deal with and their limited space. It is interesting to note that the decisions made by the retail level to process return authorizations in 
order to clear their own shelves and backroom, without realizing or acknowledging the affect their decision has on their internal partners, the warehouse.

The findings of this study for each of the three strategies along the different levels have been summarized in Table 4 below. To the best of our knowledge, the findings in the bolded text are not mirrored in the literature.

\section{Table 4.}

Key findings of this study.

\begin{tabular}{|c|c|c|}
\hline Level & Strategy & Findings \\
\hline \multirow{3}{*}{ Strategic } & Information Sharing & $\begin{array}{l}\text { - Agility and speed to respond to any fluctuations } \\
\text { Sales information helps with better decision making in regards to } \\
\text { inventory and can also allow for better planning in regards to future } \\
\text { production } \\
\text { Sharing inventory levels allow for more accurate inventory control } \\
\text { and improve order processing times, as well as schedule shipments } \\
\text { accordingly }\end{array}$ \\
\hline & Visibility & $\begin{array}{l}\text { Ability to forecast and conduct the trend analyses } \\
\text { Create better forecasts throughout all areas of the business which } \\
\text { reduce costs, increase profits, and improve supply chain operations and } \\
\text { performances } \\
\text { Ensure teams are not over buying } \\
\text { - End-to-end visibility increases confidence amongst partners and } \\
\text { ensures teams are not over buying inventory } \\
\text { - Ensures everyone works together }\end{array}$ \\
\hline & Collaboration & $\begin{array}{l}\text { Enable the organization to work with various partners } \\
\text { Reduces costs from excess inventory } \\
\text { Can help strengthen the supply chain } \\
\text { Ensure the right products are on the shelf at the right time } \\
\end{array}$ \\
\hline \multirow{3}{*}{ Warehouse } & Information Sharing & $\begin{array}{l}\text { - Creates accountability for vendors to ensure the inventory is sent } \\
\text { correctly } \\
\text { - Reduces the excessive use of resources } \\
\text { - Know when the asset becomes a liability } \\
\text { - Make more informed decisions as it moderates any unpredictability } \\
\text { - Increases the chances of reduced inventory levels } \\
\text { - Allows for better planning of resources better plan schedules and day } \\
\text { to day } \\
\text { - More items are processed, which result in higher turnovers } \\
\text { - More time to resolve and adapt to uncertainties }\end{array}$ \\
\hline & Visibility & $\begin{array}{l}\text { - Reduce any abrupt planning which forces the team to overuse } \\
\text { resources } \\
\text { - Teams are more cognizant of what is happening across different } \\
\text { areas, and which areas may need improvements } \\
\text { - Increase in visibility lowers costs } \\
\text { - Faster receiving times, and processing times } \\
\text { - Reduce any variability and create consistencies } \\
\end{array}$ \\
\hline & Collaboration & $\begin{array}{l}\text { - Build trust and confidence amongst partners } \\
\text { - Helps plan company's resources accordingly } \\
\text { Advance planning of seasonal merchandise to capture sales before } \\
\text { competitors }\end{array}$ \\
\hline
\end{tabular}




\begin{tabular}{|c|c|c|}
\hline \multirow{3}{*}{ Retail } & Information Sharing & $\begin{array}{l}\text { Helps plan their resources and floor plans } \\
\text { - Clear floor and backroom space for newer seasonal merchandise } \\
\text { - Lower non-productive inventory rate as excess seasonal is } \\
\text { majority shipped back to distribution centres } \\
\text { - Increase in sales } \\
\text { - Cycle out inventory } \\
\text { Quick replenishments } \\
\text { - Results in a decrease in excess seasonal inventory } \\
\text { - Smooth inventory turnover } \\
\text { - Controlled in-stock inventory }\end{array}$ \\
\hline & Visibility & $\begin{array}{l}\text { - Generating better forecasts to achieve a goal of reduced costs and } \\
\text { increased profits } \\
\text { - Planning future return authorizations } \\
\text { - Monitoring sales } \\
\text { - Conduct analyses' } \\
\text { - Ability to adjust according to needs } \\
\text { - Less pressure for the retail management team due to automation }\end{array}$ \\
\hline & Collaboration & $\begin{array}{l}\text { Collaborative effort to reach and exceed key performance measures } \\
\text { in place } \\
\text { - Work with multiple partners to ensure there is an agreed level of } \\
\text { inventory flow } \\
\text { - Reduces any variances involved in individual decision making } \\
\cdot \text { Reduces risks }\end{array}$ \\
\hline
\end{tabular}

\subsection{Limitations}

This study has several limitations. One of these limitations was the lack of a vendor's perspective. For this study, efforts were made to access vendors however all attempts were unsuccessful due to the non-disclosure agreements in place. A vendors' perspective could have provided this study with an external viewpoint on the organizations policies and practices and how the relationship could potentially influence the three strategies. Another limitation is the researchers' ability to examine the impact of the tools used by the organization. This was due to a lack of information that would be required to statistically test the impact of these tools on the organizations performance.

This study was conducted focusing on a multi-national retailer located in North America with some specific characteristics which were described in Section 1. Given these characteristics, the findings from this study may not be generalized for retailers with different characteristics. This could be due to a variety of reasons such as the capital available, as they may have the 
financial capability to implement these tools and strategies in comparison to smaller organizations. The overall size of the organization as well as the product mix offered by the retailer could also potentially impact the applicability of this study.

The final limitation is related to the data collection method utilized for this study (i.e. semi-structured interviews). In addition, through the process of conducting the interviews, it is possible for the interviewees to be influenced by the situation and be unconsciously biased. This is a possibility due to the interviewee being unconsciously unaware of the influences of their internal reactions on being interviewed regarding a certain topic (Diefenbach, 2009).

\subsection{Further Research Possibilities}

This research opens the door to further investigation. In noting the limitations of this study, further research can be conducted with an additional level (e.g., the vendor level). This is because the vendor's ability to perform consistently in-line with an organizations objectives can positively impact the organizations performances (Jajja, Kannan, Brah, \& Hassan, 2016). Considering this, a vendor's perspective can add insight into the relationship between the organization and an external partner, as well as how this could influence or add further insight into the impact of three discussed strategies. Another future research possibility can be the statistical testing on the impacts of the tools used by the organization and its effects on performances. This would translate in to a quantitative research method which allow for a deeper, different understanding of the tools and strategies. Lastly, based on the findings that were not supported by the literature, further studies can be conducted in order to identify additional factors that could have an impact on the outcome of the strategies. 


\section{Appendix A - Interview Questions}

STRATEGY - INTER VIEW SCRIPT

\begin{tabular}{cll}
\hline Category & Q\# & Question \\
\hline Consent & $\begin{array}{l}\text { Participants will be given a consent form to sign. Upon consent, the participants will be given a } \\
\text { written questionnaire, and the interview will begin }\end{array}$ \\
\hline Goal of the research, in-depth & $\begin{array}{l}\text { The goal of the research is to identify and explore how different pieces of information shared, } \\
\text { various tools to increase visibility, as well as different methods of collaboration can help retailers } \\
\text { reduce a loss in profits from excess seasonal inventory. Through interviews, the goal is to gain an } \\
\text { understanding of the different pieces of information that is shared with the retail level, as well as } \\
\text { visibility tools and collaboration methods, and the benefits derived from each. }\end{array}$ \\
\hline Opening & 1 & What strategic KPI's do you have in place to monitor inventory? \\
\hline Opening & Do you have any policies or strategies in place to manage seasonal inventory? \\
\hline
\end{tabular}

a) Do you return the goods the to vendor?

b) Are you able to sell the excess inventory to

an outlet retailer?

Opening 3 How do you address the issue of excess inventory? What do you do with the excess inventory? c) Do you donate the excess inventory?

d) Do you destroy the excess inventory?

e) Other than the ones mentioned, is there any

other step you take?

\begin{tabular}{|c|c|c|c|c|}
\hline Overview & & $\begin{array}{l}\text { Based on the available literature, it has been noted that information sharing, visibility, and } \\
\text { collaboration play a vital role in many areas of a supply chain. I want to gain a better } \\
\text { understanding of each strategy, and how beneficial each is at the retail level. I will first start off by } \\
\text { asking questions regarding information sharing. }\end{array}$ & & \\
\hline Information Sharing - Definition & & $\begin{array}{l}\text { Information sharing is defined as the extent to which proprietary and critical information is shared } \\
\text { between supply chain members and a "willingness to make strategic and tactical data available to } \\
\text { other members of the supply chain" }\end{array}$ & & $\begin{array}{l}\text { (Koçoğlu, İmamoğlu, İnce, \& } \\
\text { Keskin, 2011; as cited in } \\
\text { Mentzer, 2001, p.11) }\end{array}$ \\
\hline Information Sharing & 4 & Is there any information sharing policy in place or practice? & $\begin{array}{l}\text { a) Between Vendors and the DC's? } \\
\text { b) Between Vendors and the Retail stores? }\end{array}$ & \\
\hline If yes in 4 & & What are the expected benefits from having this policy in place? & & \\
\hline If no in 4 & & Is an information sharing policy something you would consider? & & \\
\hline If no in 4 & & Why not? & & \\
\hline
\end{tabular}




\begin{tabular}{|c|c|c|c|c|}
\hline Visibility - Overview & & $\begin{array}{l}\text { Now that we have discussed information sharing, I would like to ask a few questions regarding } \\
\text { visibility. }\end{array}$ & & \\
\hline Visibility - Definition & & $\begin{array}{l}\text { Visibility is defined as "the identity, location and status of entities transiting the supply chain, } \\
\text { captured in timely messages about events, along with the planned and actual dates/times for these } \\
\text { events". }\end{array}$ & & (Francis, 2008, p.3) \\
\hline Visibility & 6 & Does your organization utilize any tools to increase visibility? & & \\
\hline If no in 6 & & Why not? & & \\
\hline If no in 6 & & Is this something you believe could be helpful? & & \\
\hline Visibility & 7 & What tools do you use to aid in increasing visibility? & $\begin{array}{l}\text { a) RFID, Radio Frequency Identification } \\
\text { b) ERP, Enterprise Resource Planning } \\
\text { c) Integrated POS systems } \\
\text { d) Other than the ones mentioned, are there } \\
\text { any other tools you use? }\end{array}$ & $\begin{array}{l}\text { (Rekik, Syntetos, \& Jemai, } \\
\text { 2015; Cotteleer and Bendoly, } \\
\text { 2006; D’Angelo, 2018; as cited } \\
\text { in Cook, Heister, \& Sengupta, } \\
\text { 2011) }\end{array}$ \\
\hline Visibility & 8 & What kind of benefits do you notice when using these visibility tools? & & \\
\hline Visibility - Closing & 9 & Is there anything else you would like to add in regards to visibility, and the tools utilized? & & \\
\hline Collaboration - Overview & & Now that we have discussed visibility, I would like to ask a few questions regarding collaboration & & \\
\hline Collaboration - Definition & & $\begin{array}{l}\text { Collaboration within a supply chain environment occurs when two or more independent } \\
\text { companies work together to jointly achieve greater success than what can be achieved by just } \\
\text { working alone. }\end{array}$ & & (Daugherty et al, 2006) \\
\hline Collaboration & 10 & Does your organization collaborate with vendors? & & \\
\hline If no in 10 & & Why not? & & \\
\hline If no in 10 & & Is this something you believe could be helpful? & & \\
\hline If yes in 10 & & Which members do you collaborate with? & & \\
\hline Collaboration & 11 & What method of collaboration does your organization use? & $\begin{array}{l}\text { a) CPFR, Collaborative planning, forecasting, } \\
\text { and replenishment } \\
\text { b) ECR, Efficient consumer response } \\
\text { c) VMI, Vendor-managed inventory } \\
\text { d) CRP, Continuous replenishment programs } \\
\text { e) Other than the ones mentioned, are there } \\
\text { any other forms of collaboration you use? }\end{array}$ & $\begin{array}{l}\text { (as cited in Cook, Heiser, \& } \\
\text { Sengupta, 2011; Cho and Lee, } \\
\text { 2013) }\end{array}$ \\
\hline Collaboration & 12 & $\begin{array}{l}\text { Based on the method of collaboration you stated, what characteristics do you look for when } \\
\text { collaborating with vendors? }\end{array}$ & $\begin{array}{l}\text { a) Company partners } \\
\text { b) Characteristics such as size or type }\end{array}$ & \\
\hline Collaboration & 13 & What kind of benefits do you note from collaborating with these vendors? & What are the expected benefits? & \\
\hline Collaboration & 14 & What KPI's (key performance indicators) do you have in place to monitor vendor collaboration? & & (McDonald, 2018) \\
\hline llaboration - Closing & 15 & Is there anything else you would like to add in regards to collaboration? & & \\
\hline Closing & 16 & $\begin{array}{l}\text { I really appreciate the time you took for this interview. Is there anything else } \\
\text { you think would be helpful for me to know? Or anything you might want to add? }\end{array}$ & & $\begin{array}{l}\text { (Interview Schedule Sample } \\
\text { Template, 2006) }\end{array}$ \\
\hline Closing & - & $\begin{array}{l}\text { I should have all the information I need. Would it be alright to contact you if I have any more } \\
\text { questions? Thank you very much! }\end{array}$ & & $\begin{array}{l}\text { (Interview Schedule Sample } \\
\text { Template, 2006) }\end{array}$ \\
\hline
\end{tabular}


WAREHOUSE OPERATIONS - INTERVIEW SCRIPT

\begin{tabular}{|c|c|c|c|c|}
\hline Category & Q\# & Question & Potential Prompts & Reference \\
\hline Consent & & $\begin{array}{l}\text { Participants will be given a consent form to sign. Upon consent, the participants will be } \\
\text { given a written questionnaire, and the interview will begin }\end{array}$ & & \\
\hline Goal of the research, in-depth & & $\begin{array}{l}\text { The goal of the research is to identify and explore how different pieces of information } \\
\text { shared, various tools to increase visibility, as well as different methods of collaboration can } \\
\text { help retailers reduce a loss in profits from excess seasonal inventory. Through interviews, } \\
\text { the goal is to gain an understanding of the different pieces of information that is shared with } \\
\text { a retailer, as well as visibility tools and collaboration methods, and the benefits derived } \\
\text { from each. }\end{array}$ & & \\
\hline Opening & 1 & What operational KPI's do you have in place to monitor inventory? & & (McDonald, 2018) \\
\hline Opening & 2 & Within a full fiscal year, how often do you address excess seasonal inventory? & $\begin{array}{l}\text { a) Once every season (four) } \\
\text { b) Twice a year } \\
\text { c) Once a year } \\
\text { d) Not at all }\end{array}$ & \\
\hline Overview & & $\begin{array}{l}\text { Based on the available literature, it has been noted that information sharing, visibility, and } \\
\text { collaboration play a vital role in many areas of a supply chain. I want to gain a better } \\
\text { understanding of each strategy, and how beneficial each is at the retail level. I will first start } \\
\text { off by asking questions regarding information sharing. }\end{array}$ & & \\
\hline Information Sharing - Definition & & $\begin{array}{l}\text { Information sharing is defined as the extent to which proprietary and critical information is } \\
\text { shared between supply chain members and a "willingness to make strategic and tactical } \\
\text { data available to other members of the supply chain" }\end{array}$ & & $\begin{array}{l}\text { (Koçoğlu, İmamoğlu, İnce, \& } \\
\text { Keskin, 2011; as cited in } \\
\text { Mentzer, 2001, p.11) }\end{array}$ \\
\hline Warm-up & 3 & What pieces of information is currently shared with you? & Location, product condition inventory levels & \\
\hline Warm-up & 4 & Do you see any benefits from this information being shared? & & \\
\hline $\begin{array}{l}\text { Information Sharing - location of the } \\
\text { product within the supply chain }\end{array}$ & 5 & $\begin{array}{l}\text { On a scale of } 1 \text { to } 5 \text { (where } 1 \text {, has no importance; } 2 \text { is rather important; } 3 \text { is important; } 4 \text {, } \\
\text { very important; and } 5 \text {, is vital), how important is the location of the product from the } \\
\text { vendor? }\end{array}$ & & \multirow{6}{*}{ (Lumsden \& Mirzabeiki, 2008) } \\
\hline$"$ & $5 \mathrm{a}$ & Is this a piece of information that is shared with you? & & \\
\hline If yes in $5 \mathrm{a}$ & & $\begin{array}{l}\text { Based on the KPI's mentioned, do you notice any benefits from having this information } \\
\text { shared with you? }\end{array}$ & & \\
\hline If no in $5 \mathrm{a}$ & $5 \mathrm{~b}$ & Is this a piece of information you believe could be helpful? & & \\
\hline If no in $5 b$ & & Why not? & & \\
\hline If yes in $5 b$ & & How? & & \\
\hline $\begin{array}{l}\text { Information Sharing - condition of the } \\
\text { products while they are in the } \\
\text { shipment }\end{array}$ & 6 & $\begin{array}{l}\text { On a scale of } 1 \text { to } 5 \text { (where } 1 \text {, has no importance; } 2 \text { is rather important; } 3 \text { is important; } 4 \text {, } \\
\text { very important; and } 5 \text {, is vital), how important is it to know the condition of the products } \\
\text { while they are in the shipment? }\end{array}$ & & \multirow{6}{*}{ (Lumsden \& Mirzabeiki, 2008) } \\
\hline$"$ & $6 \mathrm{a}$ & Is this a piece of information that is shared with you? & & \\
\hline If yes in $6 a$ & & $\begin{array}{l}\text { Based on the KPI's mentioned, do you notice any benefits from having this information } \\
\text { shared with you? }\end{array}$ & & \\
\hline If no in $6 \mathrm{a}$ & $6 \mathrm{~b}$ & Is this a piece of information you believe could be helpful? & & \\
\hline If no in $6 b$ & & Why not? & & \\
\hline If yes in $6 b$ & & How? & & \\
\hline
\end{tabular}




\begin{tabular}{|c|c|c|c|c|}
\hline $\begin{array}{l}\text { Information Sharing - position and } \\
\text { sequence of products in inventory }\end{array}$ & 7 & $\begin{array}{l}\text { On a scale of } 1 \text { to } 5 \text { (where } 1 \text {, has no importance; } 2 \text { is rather important; } 3 \text { is important; } 4 \text {, } \\
\text { very important; and } 5 \text {, is vital), how important is it to know the position and sequence of } \\
\text { products in inventory at the vendors DC? }\end{array}$ & $\begin{array}{l}\text { Position and sequence: having exact } \\
\text { knowledge on the location of inventory to } \\
\text { improve time efficiencies and add value }\end{array}$ & \multirow{6}{*}{ (Lumsden \& Mirzabeiki, 2008) } \\
\hline$"$ & $7 \mathrm{a}$ & Is this a piece of information that is shared with you? & & \\
\hline If yes in $7 \mathrm{a}$ & & $\begin{array}{l}\text { Based on the KPI's mentioned, do you notice any benefits from having this information } \\
\text { shared with you? }\end{array}$ & & \\
\hline If no $7 \mathrm{a}$ & $7 \mathrm{~b}$ & Is this a piece of information you believe could be helpful? & & \\
\hline If no in $7 \mathrm{~b}$ & & Why not? & & \\
\hline If yes in $7 \mathrm{~b}$ & & How? & & \\
\hline $\begin{array}{l}\text { Information Sharing - retail inventory } \\
\text { levels }\end{array}$ & 8 & $\begin{array}{l}\text { On a scale of } 1 \text { to } 5 \text { (where } 1 \text {, has no importance; } 2 \text { is rather important; } 3 \text { is important; } 4 \text {, } \\
\text { very important; and } 5 \text {, is vital), how important is it to know your own inventory levels? }\end{array}$ & $\begin{array}{l}\text { So, how important is being aware of your own } \\
\text { inventory? }\end{array}$ & \multirow{6}{*}{ (Lumsden \& Mirzabeiki, 2008) } \\
\hline " & $8 \mathrm{a}$ & Is this information that you have ready access to? & & \\
\hline If yes in $8 \mathrm{a}$ & & $\begin{array}{l}\text { Based on the KPI's mentioned, do you notice any benefits from having this information } \\
\text { shared with you? }\end{array}$ & & \\
\hline If no in $8 \mathrm{a}$ & $8 \mathrm{~b}$ & Is this a piece of information you believe could be helpful? & & \\
\hline If no in $8 b$ & & Why not? & & \\
\hline If yes in $8 b$ & & How? & & \\
\hline Information Sharing - lead times & 9 & $\begin{array}{l}\text { On a scale of } 1 \text { to } 5 \text { (where } 1 \text {, has no importance; } 2 \text { is rather important; } 3 \text { is important; } 4 \text {, } \\
\text { very important; and } 5 \text {, is vital), how important is it to have vendor lead time information } \\
\text { shared with you? }\end{array}$ & Receiving times & \multirow{6}{*}{$\begin{array}{l}\text { (as cited in Lumsden \& } \\
\text { Mirzabeiki, } 2008 \text { by Bowersox, } \\
\text { Closs, \& Cooper, 2007) }\end{array}$} \\
\hline " & $9 \mathrm{a}$ & Is this a piece of information that is shared with you? & & \\
\hline If yes in $9 \mathrm{a}$ & & $\begin{array}{l}\text { Based on the KPI's mentioned, do you notice any benefits from having this information } \\
\text { shared with you? }\end{array}$ & & \\
\hline If no in 9a & $9 \mathrm{~b}$ & Is this a piece of information you believe could be helpful? & & \\
\hline If no in $9 \mathrm{~b}$ & & Why not? & & \\
\hline If yes in $9 b$ & & How? & & \\
\hline $\begin{array}{l}\text { Information Sharing - shipping } \\
\text { quantity }\end{array}$ & 10 & $\begin{array}{l}\text { On a scale of } 1 \text { to } 5 \text { (where } 1 \text {, has no importance; } 2 \text { is rather important; } 3 \text { is important; } 4 \text {, } \\
\text { very important; and } 5 \text {, is vital), how important is it to have shipping quantity information } \\
\text { shared with you? }\end{array}$ & Batch size & \multirow{6}{*}{$\begin{array}{l}\text {-(Lumsden \& Mirzabeiki, 2008; } \\
\text {-Zhang, Tan, Robb, \& Zheng, } \\
\text {-2006) }\end{array}$} \\
\hline " & $10 \mathrm{a}$ & Is this a piece of information that is currently shared with you? & & \\
\hline If yes in $10 \mathrm{a}$ & & What benefits do you notice from having this information being shared with you? & & \\
\hline If no in $10 \mathrm{a}$ & $10 \mathrm{~b}$ & Is this a piece of information you believe could be helpful? & & \\
\hline If no in $10 \mathrm{~b}$ & & Why not? & & \\
\hline If yes in $10 \mathrm{~b}$ & & How? & & \\
\hline Information Sharing - sales history & 11 & $\begin{array}{l}\text { On a scale of } 1 \text { to } 5 \text { (where } 1 \text {, has no importance; } 2 \text { is rather important; } 3 \text { is important; } 4 \text {, } \\
\text { very important; and } 5 \text {, is vital), how important is it to know the sales history at the retail } \\
\text { location? }\end{array}$ & & \multirow{6}{*}{ (Lumsden \& Mirzabeiki, 2008) } \\
\hline " & $11 \mathrm{a}$ & Is this information that you have ready access to? & & \\
\hline If yes in $11 \mathrm{a}$ & & What benefits do you notice from having this information? & & \\
\hline If no in $11 \mathrm{a}$ & $11 \mathrm{~b}$ & Is this a piece of information you believe could be helpful? & & \\
\hline If no in $11 \mathrm{~b}$ & & Why not? & & \\
\hline If no in $11 b$ & & How? & & \\
\hline
\end{tabular}




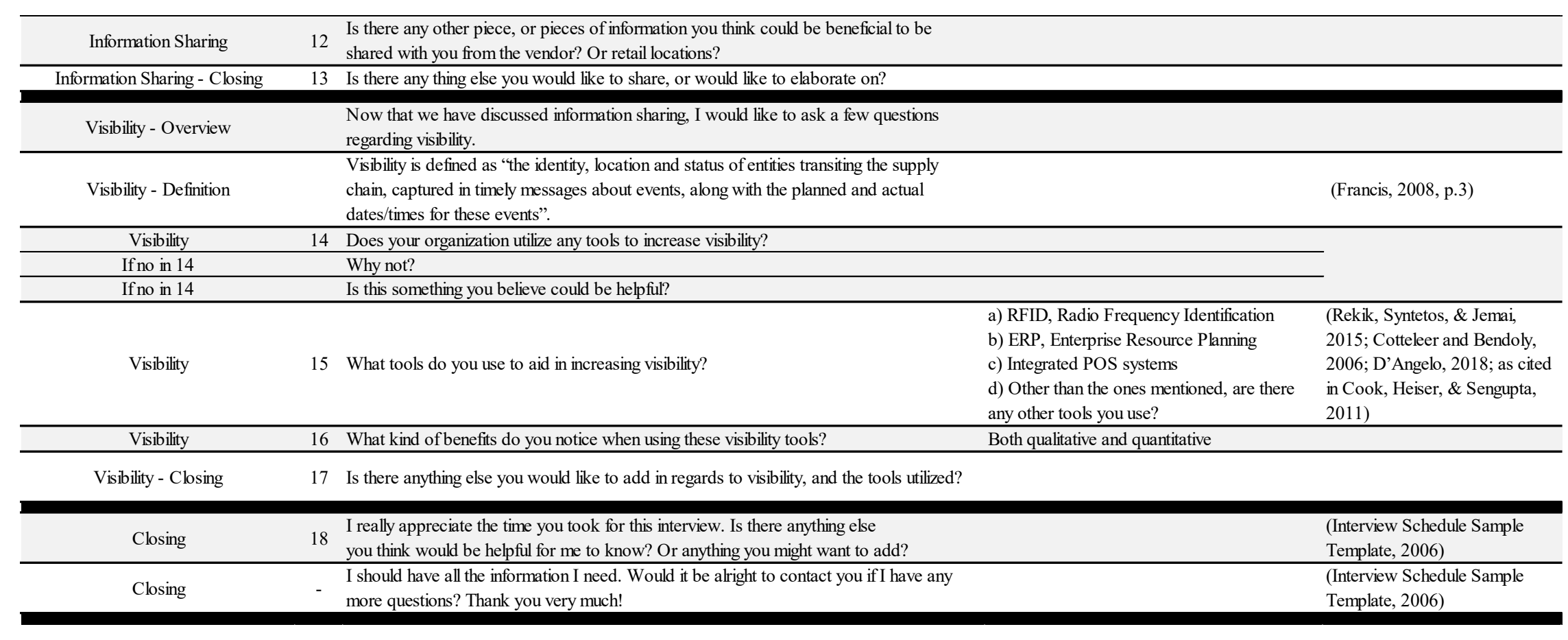


RETAIL OPERATIONS - INTERVIEW SCRIPT

\begin{tabular}{|c|c|c|c|c|}
\hline Category & Q\# & Question & Potential Prompts & Reference \\
\hline Consent & & $\begin{array}{l}\text { Participants will be given a consent form to sign. Upon consent, the participants will be } \\
\text { given a written questionnaire, and the interview will begin }\end{array}$ & & \\
\hline Goal of the research, in-depth & & $\begin{array}{l}\text { The goal of the research is to identify and explore how different pieces of information } \\
\text { shared, various tools to increase visibility, as well as different methods of collaboration can } \\
\text { help retailers reduce a loss in profits from excess seasonal inventory. Through interviews, } \\
\text { the goal is to gain an understanding of the different pieces of information that is shared with } \\
\text { the retail level, as well as visibility tools and collaboration methods, and the benefits } \\
\text { derived from each. }\end{array}$ & & \\
\hline Opening & 1 & What operational KPI's do you have in place to monitor inventory? & & (McDonald, 2018) \\
\hline Opening & 2 & Within a full fiscal year, how often do you address excess seasonal inventory? & $\begin{array}{l}\text { a) Once every season (four) } \\
\text { b) Twice a year } \\
\text { c) Once a year } \\
\text { d) Not at all }\end{array}$ & \\
\hline Overview & & $\begin{array}{l}\text { Based on the available literature, it has been noted that information sharing, visibility, and } \\
\text { collaboration play a vital role in many areas of a supply chain. I want to gain a better } \\
\text { understanding of each strategy, and how beneficial each is at the retail level. I will first start } \\
\text { off by asking questions regarding information sharing. }\end{array}$ & & \\
\hline Information Sharing - Definition & & $\begin{array}{l}\text { Information sharing is defined as the extent to which proprietary and critical information is } \\
\text { shared between supply chain members and a "willingness to make strategic and tactical } \\
\text { data available to other members of the supply chain" }\end{array}$ & & $\begin{array}{l}\text { (Koçoğlu, İmamoğlu, İnce, \& } \\
\text { Keskin, 2011; as cited in } \\
\text { Mentzer, 2001, p.11) } \\
\end{array}$ \\
\hline Warm-up & 3 & What pieces of information is currently shared with you? & Location, condition inventory levels & \\
\hline Warm-up & 4 & Do you see any benefits from this information being shared? & & \\
\hline $\begin{array}{l}\text { Information Sharing - location of the } \\
\text { product within the supply chain }\end{array}$ & 5 & $\begin{array}{l}\text { On a scale of } 1 \text { to } 5 \text { (where } 1 \text {, has no importance; } 2 \text { is rather important; } 3 \text { is important; } 4 \text {, } \\
\text { very important; and } 5 \text {, is vital), how important is the location of the product at the } \\
\text { distribution center? }\end{array}$ & & \\
\hline$"$ & $5 \mathrm{a}$ & Is this a piece of information that is shared with you? & & \\
\hline If yes in $5 \mathrm{a}$ & & $\begin{array}{l}\text { Based on the KPI's mentioned, do you notice any benefits from having this information } \\
\text { shared with you? }\end{array}$ & & (Lumsden \& Mirzabeiki, 2008) \\
\hline If no in $5 \mathrm{a}$ & $5 \mathrm{~b}$ & Is this a piece of information you believe could be helpful? & & \\
\hline If no in $5 b$ & & Why not? & & \\
\hline If yes in $5 b$ & & How? & & \\
\hline $\begin{array}{l}\text { Information Sharing - condition of the } \\
\text { products while they are in the } \\
\text { shipment }\end{array}$ & 6 & $\begin{array}{l}\text { On a scale of } 1 \text { to } 5 \text { (where } 1 \text {, has no importance; } 2 \text { is rather important; } 3 \text { is important; } 4 \text {, } \\
\text { very important; and } 5 \text {, is vital), how important is it to know the condition of the products } \\
\text { while they are in the shipment? }\end{array}$ & & \\
\hline$"$ & $6 \mathrm{a}$ & Is this a piece of information that is shared with you? & & \\
\hline If yes in $6 \mathrm{a}$ & & $\begin{array}{l}\text { Based on the KPI's mentioned, do you notice any benefits from having this information } \\
\text { shared with you? }\end{array}$ & & (Lumsden \& Mirzabeiki, 2008) \\
\hline If no in $6 \mathrm{a}$ & $6 \mathrm{~b}$ & Is this a piece of information you believe could be helpful? & & \\
\hline If no in $6 \mathrm{~b}$ & & Why not? & & \\
\hline If yes in $6 \mathrm{~b}$ & & How? & & \\
\hline
\end{tabular}




\begin{tabular}{|c|c|c|c|c|}
\hline $\begin{array}{l}\text { Information Sharing - position and } \\
\text { sequence of products in inventory }\end{array}$ & 7 & $\begin{array}{l}\text { On a scale of } 1 \text { to } 5 \text { (where } 1 \text {, has no importance; } 2 \text { is rather important; } 3 \text { is important; } 4 \text {, } \\
\text { very important; and } 5 \text {, is vital), how important is it to know the position and sequence of } \\
\text { products in inventory at the distribution center? }\end{array}$ & $\begin{array}{l}\text { Position and sequence: having exact } \\
\text { knowledge on the location of inventory to } \\
\text { improve time efficiencies and add value }\end{array}$ & \multirow{6}{*}{ (Lumsden \& Mirzabeiki, 2008) } \\
\hline " & $7 \mathrm{a}$ & Is this a piece of information that is shared with you? & & \\
\hline If yes in $7 \mathrm{a}$ & & $\begin{array}{l}\text { Based on the KPI's mentioned, do you notice any benefits from having this information } \\
\text { shared with you? }\end{array}$ & & \\
\hline If no $7 \mathrm{a}$ & $7 \mathrm{~b}$ & Is this a piece of information you believe could be helpful? & & \\
\hline If no in $7 b$ & & Why not? & & \\
\hline If yes in $7 \mathrm{~b}$ & & How? & & \\
\hline $\begin{array}{l}\text { Information Sharing - retail inventory } \\
\text { levels }\end{array}$ & 8 & $\begin{array}{l}\text { On a scale of } 1 \text { to } 5 \text { (where } 1 \text {, has no importance; } 2 \text { is rather important; } 3 \text { is important; } 4 \text {, } \\
\text { very important; and } 5 \text {, is vital), how important is it to know your own inventory levels? }\end{array}$ & $\begin{array}{l}\text { So, how important is being aware of your own } \\
\text { inventory? }\end{array}$ & \multirow{6}{*}{ (Lumsden \& Mirzabeiki, 2008) } \\
\hline$"$ & $8 \mathrm{a}$ & Is this information that you have ready access to? & & \\
\hline If yes in $8 \mathrm{a}$ & & $\begin{array}{l}\text { Based on the KPI's mentioned, do you notice any benefits from having this information } \\
\text { shared with you? }\end{array}$ & & \\
\hline If no in $8 \mathrm{a}$ & $8 \mathrm{~b}$ & Is this a piece of information you believe could be helpful? & & \\
\hline If no in $8 b$ & & Why not? & & \\
\hline If yes in $8 b$ & & How? & & \\
\hline Information Sharing - lead times & 9 & $\begin{array}{l}\text { On a scale of } 1 \text { to } 5 \text { (where } 1 \text {, has no importance; } 2 \text { is rather important; } 3 \text { is important; } 4 \text {, } \\
\text { very important; and } 5 \text {, is vital), how important is it to have lead time information shared } \\
\text { with you? }\end{array}$ & Receiving times & \multirow{6}{*}{$\begin{array}{l}\text { (as cited in Lumsden \& } \\
\text { Mirzabeiki, } 2008 \text { by Bowersox, } \\
\text { Closs, \& Cooper, 2007) }\end{array}$} \\
\hline$"$ & $9 \mathrm{a}$ & Is this a piece of information that is shared with you? & & \\
\hline If yes in $9 \mathrm{a}$ & & $\begin{array}{l}\text { Based on the KPI's mentioned, do you notice any benefits from having this information } \\
\text { shared with you? }\end{array}$ & & \\
\hline If no in $9 \mathrm{a}$ & $9 \mathrm{~b}$ & Is this a piece of information you believe could be helpful? & & \\
\hline If no in $9 b$ & & Why not? & & \\
\hline If yes in $9 \mathrm{~b}$ & & How? & & \\
\hline $\begin{array}{l}\text { Information Sharing - shipping } \\
\text { quantity }\end{array}$ & 10 & $\begin{array}{l}\text { On a scale of } 1 \text { to } 5 \text { (where } 1 \text {, has no importance; } 2 \text { is rather important; } 3 \text { is important; } 4 \text {, } \\
\text { very important; and } 5 \text {, is vital), how important is it to have shipping quantity information } \\
\text { shared with you? }\end{array}$ & Batch size & \multirow{6}{*}{$\begin{array}{l}\text {-(Lumsden \& Mirzabeiki, 2008; } \\
\text {-Zhang, Tan, Robb, \& Zheng, } \\
\text {-2006) }\end{array}$} \\
\hline$"$ & $10 \mathrm{a}$ & Is this a piece of information that is currently shared with you? & & \\
\hline If yes in $10 \mathrm{a}$ & & What benefits do you notice from having this information being shared with you? & & \\
\hline If no in $10 \mathrm{a}$ & $10 \mathrm{~b}$ & Is this a piece of information you believe could be helpful? & & \\
\hline If no in $10 \mathrm{~b}$ & & Why not? & & \\
\hline If yes in $10 \mathrm{~b}$ & & How? & & \\
\hline Information Sharing & 11 & $\begin{array}{l}\text { Is there any other piece, or pieces of information you think could be beneficial to be } \\
\text { shared with you from the distribution center? }\end{array}$ & & \\
\hline
\end{tabular}




\begin{tabular}{|c|c|c|c|c|}
\hline Visibility - Overview & & $\begin{array}{l}\text { Now that we have discussed information sharing, I would like to ask a few questions } \\
\text { regarding visibility. }\end{array}$ & & \\
\hline Visibility - Definition & & $\begin{array}{l}\text { Visibility is defined as "the identity, location and status of entities transiting the supply } \\
\text { chain, captured in timely messages about events, along with the planned and actual } \\
\text { dates/times for these events". }\end{array}$ & & (Francis, 2008, p.3) \\
\hline Visibility & 13 & Does your organization utilize any tools to increase visibility? & & \\
\hline If no in 13 & & Why not? & & \\
\hline If no in 13 & & Is this something you believe could be helpful? & & \\
\hline Visibility & 14 & What tools do you use to aid in increasing visibility? & $\begin{array}{l}\text { a) RFID, Radio Frequency Identification } \\
\text { b) ERP, Enterprise Resource Planning } \\
\text { c) Integrated POS systems } \\
\text { d) Other than the ones mentioned, are there } \\
\text { any other tools you use? }\end{array}$ & $\begin{array}{l}\text { (Rekik, Syntetos, \& Jemai, } \\
\text { 2015; Cotteleer and Bendoly, } \\
\text { 2006; D'Angelo, 2018; as cited } \\
\text { in Cook, Heiser, \& Sengupta, } \\
\text { 2011) }\end{array}$ \\
\hline Visibility & 15 & What kind of benefits do you notice when using these visibility tools? & & \\
\hline Visibility - Closing & 16 & Is there anything else you would like to add in regards to visibility, and the tools utilized? & & \\
\hline Closing & 17 & $\begin{array}{l}\text { I really appreciate the time you took for this interview. Is there anything else } \\
\text { you think would be helpful for me to know? Or anything you might want to add? }\end{array}$ & & $\begin{array}{l}\text { (Interview Schedule Sample } \\
\text { Template, 2006) }\end{array}$ \\
\hline Closing & - & $\begin{array}{l}\text { I should have all the information I need. Would it be alright to contact you if I have any } \\
\text { more questions? Thank you very much! }\end{array}$ & & $\begin{array}{l}\text { (Interview Schedule Sample } \\
\text { Template, 2006) }\end{array}$ \\
\hline
\end{tabular}


VENDOR - INTERVIEW SCRIPT

\begin{tabular}{|c|c|c|c|c|}
\hline Category & $\mathbf{Q} \#$ & Question & Potential Prompts & Reference \\
\hline Consent & & $\begin{array}{l}\text { Participants will be given a consent form to sign. Upon consent, the participants will be } \\
\text { given a written questionnaire, and the interview will begin }\end{array}$ & & \\
\hline Goal of the research, in-depth & & $\begin{array}{l}\text { The goal of the research is to identify and explore how different pieces of information } \\
\text { shared, various tools to increase visibility, as well as different methods of collaboration can } \\
\text { help retailers reduce a loss in profits from excess seasonal inventory. Through interviews, } \\
\text { the goal is to gain an understanding of the different pieces of information that is shared with } \\
\text { the retail level, as well as visibility tools and collaboration methods, and the benefits } \\
\text { derived from each. }\end{array}$ & & \\
\hline Opening & 1 & $\begin{array}{l}\text { Do you have KPI's in place to monitor the inventory for the retailer? Or are you given } \\
\text { KPI's to adhere to? }\end{array}$ & & \multirow{3}{*}{-(McDonald, 2018) } \\
\hline If yes in 1 & & Can you describe and explain the KPI's? & & \\
\hline If no in 1 & & Would the use of KPI's be beneficial for you in any way? & & \\
\hline Overview & & $\begin{array}{l}\text { Based on the available literature, it has been noted that information sharing, visibility, and } \\
\text { collaboration play a vital role in many areas of a supply chain. I want to gain a better } \\
\text { understanding of each strategy, and how beneficial each is at the retail level. I will first start } \\
\text { off by asking questions regarding information sharing. }\end{array}$ & & \\
\hline Information Sharing - Definition & & $\begin{array}{l}\text { Information sharing is defined as the extent to which proprietary and critical information is } \\
\text { shared between supply chain members and a "willingness to make strategic and tactical } \\
\text { data available to other members of the supply chain" }\end{array}$ & & $\begin{array}{l}\text { (Koçoğlu, İmamoğlu, İnce, \& } \\
\text { Keskin, 2011; as cited in } \\
\text { Mentzer, 2001, p.11) }\end{array}$ \\
\hline Warm-up & 2 & What pieces of information does the retailer currently share with you? & & \\
\hline Warm-up & 3 & Do you see any benefits from this information being shared? & & \\
\hline Information Sharing - sales history & 4 & $\begin{array}{l}\text { On a scale of } 1 \text { to } 5 \text { (where } 1 \text {, has no importance; } 2 \text { is rather important; } 3 \text { is important; } 4 \text {, } \\
\text { very important; and } 5 \text {, is vital), how important is it to know the retail sales history? }\end{array}$ & & \multirow{6}{*}{ (Lumsden \& Mirzabeiki, 2008) } \\
\hline " & $4 \mathrm{a}$ & Is this information that you have ready access to? & & \\
\hline If yes in $4 a$ & & $\begin{array}{l}\text { Based on the KPI's mentioned, do you notice any benefits from having this information } \\
\text { shared with you? }\end{array}$ & & \\
\hline If no in $4 \mathrm{a}$ & $4 \mathrm{~b}$ & Is this a piece of information you believe could be helpful? & & \\
\hline If no in $4 b$ & & Why not? & & \\
\hline If no in $4 \mathrm{~b}$ & & How? & & \\
\hline Information Sharing - Closing & 5 & $\begin{array}{l}\text { Is there any other piece, or pieces of information you think could be beneficial to be } \\
\text { shared with you? }\end{array}$ & & \\
\hline If yes in & & What are the expected benefits? & & \\
\hline
\end{tabular}




\begin{tabular}{|c|c|c|c|c|}
\hline Visibility - Overview & & $\begin{array}{l}\text { Now that we have discussed information sharing, I would like to ask a few questions } \\
\text { regarding visibility. }\end{array}$ & & \\
\hline Visibility - Definition & & $\begin{array}{l}\text { Visibility is defined as "the identity, location and status of entities transiting the supply } \\
\text { chain, captured in timely messages about events, along with the planned and actual } \\
\text { dates/times for these events". }\end{array}$ & & (Francis, 2008, p.3) \\
\hline Visibility & 7 & Does your organization utilize any tools to increase visibility? & & \\
\hline If no in 7 & & Why not? & & \\
\hline If no in 7 & & Is this something you believe could be helpful? & & \\
\hline Visibility & 8 & What tools do you use to aid in increasing visibility? & $\begin{array}{l}\text { a) RFID, Radio Frequency Identification } \\
\text { b) ERP, Enterprise Resource Planning } \\
\text { c) Integrated POS systems } \\
\text { d) Other than the ones mentioned, are there } \\
\text { any other tools you use? }\end{array}$ & $\begin{array}{l}\text { (Rekik, Syntetos, \& Jemai, } \\
\text { 2015; Cotteleer and Bendoly, } \\
\text { 2006; D'Angelo, 2018; as cited } \\
\text { in Cook, Heiser, \& Sengupta, } \\
\text { 2011) }\end{array}$ \\
\hline Visibility & 9 & What kind of benefits do you notice when using these visibility tools? & Both quantitative and qualitative & \\
\hline Visibility & 10 & $\begin{array}{l}\text { What KPI's (key performance indicators), if any, do you have in place to monitor } \\
\text { visibility? }\end{array}$ & & \\
\hline Visibility - Closing & 11 & Is there anything else you would like to add in regards to visibility, and the tools utilized? & & \\
\hline Collaboration - Overview & & $\begin{array}{l}\text { Now that we have discussed visibility, I would like to ask a few questions regarding } \\
\text { collaboration }\end{array}$ & & \\
\hline Collaboration - Definition & & $\begin{array}{l}\text { Collaboration within a supply chain environment occurs when two or more independent } \\
\text { companies work together to jointly achieve greater success than what can be achieved by } \\
\text { just working alone. }\end{array}$ & & (Daugherty et al, 2006) \\
\hline Collaboration & 12 & What method of collaboration does your organization use? & $\begin{array}{l}\text { a) CPFR, Collaborative planning, forecasting, } \\
\text { and replenishment } \\
\text { b) ECR, Efficient consumer response } \\
\text { c) VMI, Vendor-managed inventory } \\
\text { d) CRP, Continuous replenishment programs } \\
\text { e) Other than the ones mentioned, are there } \\
\text { any other forms of collaboration you use? }\end{array}$ & $\begin{array}{l}\text { (as cited in Cook, Heiser, \& } \\
\text { Sengupta, 2011; Cho and Lee, } \\
\text { 2013) }\end{array}$ \\
\hline Collaboration & 13 & What collaboration method do you specifically use for the retailer? & & \\
\hline Collaboration & 14 & What kind of benefits do you note from collaborating with the retailer? & Both quantitative and qualitative & \\
\hline Collaboration & 15 & $\begin{array}{l}\text { What KPI's (key performance indicators) do you have in place to monitor the } \\
\text { collaboration? }\end{array}$ & & (McDonald, 2018) \\
\hline Collaboration - Closing & 16 & Is there anything else you would like to add in regards to collaboration? & & \\
\hline Closing & 17 & $\begin{array}{l}\text { I really appreciate the time you took for this interview. Is there anything else } \\
\text { you think would be helpful for me to know? Or anything you might want to add? }\end{array}$ & & $\begin{array}{l}\text { (Interview Schedule Sample } \\
\text { Template, 2006) }\end{array}$ \\
\hline Closing & - & $\begin{array}{l}\text { I should have all the information I need. Would it be alright to contact you if I have any } \\
\text { more questions? Thank you very much! }\end{array}$ & & $\begin{array}{l}\text { (Interview Schedule Sample } \\
\text { Template, 2006) }\end{array}$ \\
\hline
\end{tabular}


Implemented Strategies To Handle Seasonal Inventory In A Supply Chain: A Case Study

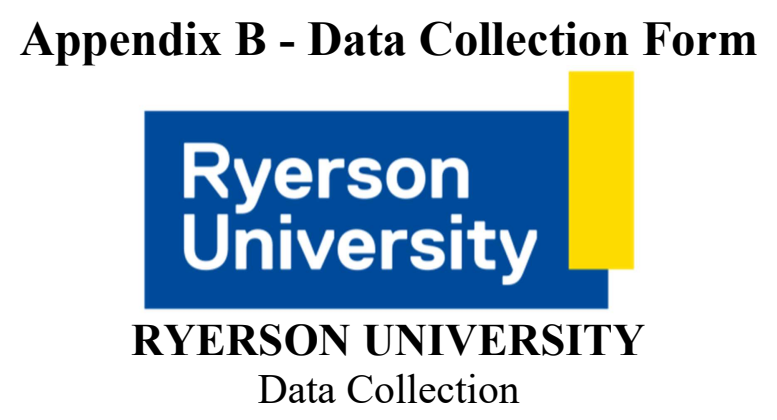

Place of Employment:

Position Title: 


\section{Appendix C - Recruitment Notices}

\section{Email Recruitment}

Hello,

My name is Haya Esrar. I am a graduate student at Ryerson University in the Yeates School of Graduate Studies. I am contacting you to see if you might be interested in participating in a research study.

This research is being done as part of my Masters project and my supervisors name is Dr. Hossein Zolfagharinia. The goal of the research is to identify and explore how different strategies can help retailers reduce a loss in profits from excess seasonal inventory. This research will focus on three strategies; information sharing, visibility, and collaboration.

If you agree to volunteer you will be asked to take part in a $30-45$ minute interview at a location with aural and visual privacy and a short questionnaire. The interview will include a series of questions related to inventory management, and seasonal inventory which will be audio recorded with your consent.

Your participation will involve a one, $30-45$-minute session, with the potential of one short follow-up discussion, all of which will be audio recorded with your consent.

The research has been reviewed and approved by the Ryerson University Research Ethics Board.

If you are interested in more information about the study or would like to volunteer, please reply to this email.

If you have any any additional questions directed towards Ryerson University Research Ethics Board, they can be contacted at rebchair@,ryerson.ca, citing the file number 2018-311.

Thank you, Haya Esrar 


\section{Email Recruitment \\ Previous Relationship with Potential Participant}

Hello,

My name is Haya Esrar. I am a graduate student at Ryerson University in the Yeates School of Graduate Studies. I am contacting you to see if you might be interested in participating in a research study.

This research is being done as part of my Masters project and my supervisors name is Dr. Hossein Zolfagharinia. The goal of the research is to identify and explore how different strategies can help retailers reduce a loss in profits from excess seasonal inventory. This research will focus on three strategies; information sharing, visibility, and collaboration.

If you agree to volunteer you will be asked to take part in a $30-45$ minute interview at a location with aural and visual privacy and a short questionnaire. The interview will include a series of questions related to inventory management, and seasonal inventory which will be audio recorded with your consent.

Your participation will involve a one, 30 - 45-minute session, with the potential of one short follow-up discussion, all of which will be audio recorded with your consent.

Your participation is completely voluntary and if you choose not to participate it will not impact our relationship.

The research has been reviewed and approved by the Ryerson University Research Ethics Board.

If you are interested in more information, about the study or would like to volunteer, please reply to this email.

If you have any any additional questions directed towards Ryerson University Research Ethics Board, they can be contacted at rebchair@,ryerson.ca, citing the file number 2018-311.

Thank you, Haya Esrar 


\section{In-Person Recruitment}

Hello,

My name is Haya Esrar. I am a graduate student at Ryerson University in the Yeates School of Graduate Studies. I am getting in touch with you to see if you might be interested in participating in a research study.

This research is being done as part of my Masters project and my supervisors name is Dr. Hossein Zolfagharinia. The goal of the research is to identify and explore how different strategies can help retailers reduce a loss in profits from excess seasonal inventory. This research will focus on three strategies; information sharing, visibility, and collaboration.

If you agree to volunteer you will be asked to take part in a $30-45$ minute interview at a location with aural and visual privacy and a short questionnaire. The interview will include a series of questions related to inventory management, and seasonal inventory which will be audio recorded with your consent.

Your participation will involve a one, 30 - 45-minute session, with the potential of one short follow-up discussion, all of which will be audio recorded with your consent.

The research has been reviewed and approved by the Ryerson University Research Ethics Board.

If you are interested in more information, about the study or would like to volunteer, you can contact me at haya.esrar@ryerson.ca.

If you have any any additional questions directed towards Ryerson University Research Ethics Board, they can be contacted at rebchair@,ryerson.ca, citing the file number 2018-311.

Thank you,

Haya Esrar 


\section{In-Person Recruitment \\ Previous Relationship with Potential Participant}

Hello,

My name is Haya Esrar. I am a graduate student at Ryerson University in the Yeates School of Graduate Studies. I am getting in touch with you to see if you might be interested in participating in a research study.

This research is being done as part of my Masters project and my supervisors name is Dr. Hossein Zolfagharinia. The goal of the research is to identify and explore how different strategies can help retailers reduce a loss in profits from excess seasonal inventory. This research will focus on three strategies; information sharing, visibility, and collaboration.

If you agree to volunteer you will be asked to take part in a $30-45$ minute interview at a location with aural and visual privacy and a short questionnaire. The interview will include a series of questions related to inventory management, and seasonal inventory which will be audio recorded with your consent.

Your participation will involve a one, 30 -45-minute session, with the potential of one short follow-up discussion, all of which will be audio recorded with your consent.

Your participation is completely voluntary and if you choose not to participate it will not impact our relationship.

The research has been reviewed and approved by the Ryerson University Research Ethics Board.

If you are interested in more information, about the study or would like to volunteer, you can contact me at haya.esrar@ryerson.ca.

If you have any any additional questions directed towards Ryerson University Research Ethics Board, they can be contacted at rebchair@,ryerson.ca, citing the file number 2018-311.

Thank you, Haya Esrar 


\section{Appendix D - Consent Form \\ Ryerson \\ University \\ RYERSON UNIVERSITY \\ Consent Agreement}

You are being invited to participate in a research study. Please read this consent form so that you understand what your participation will involve. Before you consent to participate, please ask any questions to be sure you understand what your participation will involve.

TITLE OF THE STUDY

Identifying Strategies to Mitigate Excess Seasonal Inventory

INVESTIGATORS

This research study is being conducted by myself, Haya Esrar, with the supervision of Dr. Hossein Zolfagharinia from Yeates School of Graduate Studies at Ryerson University.

If you have any questions or concerns about the research, please feel free to contact Haya Esrar at haya.esrar@ryerson.ca.

\section{PURPOSE OF THE STUDY}

The goal of the research is to identify and explore how different strategies can help retailers reduce a loss in profits from excess seasonal inventory. This research will focus on three strategies; information sharing, visibility, and collaboration. A maximum number of 20 participants will be recruited for this study.

This research is being conducted in partial completion of a graduate degree requirement which will contribute to a major research paper.

\section{WHAT YOU WILL BE ASKED TO DO}

Participants will be asked to voluntarily take part in a 30 - 45 minute interview at a location with aural and visual privacy and a short questionnaire. The interview will include a series of questions related to inventory management, different pieces of information shared, visibility tools used, as well as different methods of collaboration. The research findings can be made available to participants upon their request, and the completion of the study. Below are samples of the type of questions participants can expect:

1) On a scale of 1 to 5 (where 1, has no importance; 2 is rather important; 3 is important; 4 , very important; and 5, is vital), how important is the location of the product within the supply chain?

2) What benefits do you notice from having this information being shared with you?

\section{CRITERIA OF INCLUSION}

This study is directed towards retail, and supply chain members within an organization who have 
experience with inventory management. This includes an individual at a strategic level, a manager at the retail store level, a manager at the warehouse level, and a partnered vendor with the retail organization.

\section{POTENTIAL BENEFITS}

There is no direct benefit to you for taking part in this study. It is hoped that the research will explain how different pieces of shared information at the retail level, the use of visibility tools, and different collaboration methods can help an organization reduce a loss in profits from excess seasonal inventory. Participants can also choose to request a copy of the completed research study.

\section{WHAT ARE THE POTENTIAL RISKS TO YOU AS A PARTICIPANT}

Some of the survey questions may make you uncomfortable or you may simply wish not to answer some questions. You are free to decline to answer any questions you do not wish to answer, or stop participating at any time.

\section{CONFIDENTIALITY}

The participants' identity will remain confidential. Participants will be assigned and identified using pseudonyms throughout the entire study.

\section{DATA STORAGE}

The interviews will be audio recorded and stored in a safe and confidential file. Once the audio recordings have been transcribed and verified, the audio files will be deleted and the transcriptions will be safely stored. All data collected from the interviews will be retained for a period of two years.

\section{DATA DISSEMINATION}

Based on the collection of the data, and the completion of the research, it is hoped the study will result in a published paper.

Participants can have access to the final research paper once all graduate degree requirements have been fulfilled. This can be accessed from https://digital.library.ryerson.ca/.

\section{COMPENSATION FOR INJURY}

By agreeing to participate in this research, you are not giving up or waiving any legal right in the event that you are harmed during the research.

\section{VOLUNTARY PARTICIPATION AND WITHDRAWAL}

Participation in this study is completely voluntary. You can choose whether to be in this study or not. If any question makes you uncomfortable, you can skip that question. You may stop participating at any time. If you choose to stop participating, you may also choose to not have your data included in the study. Your choice of whether or not to participate will not influence your future relations with Ryerson University or the investigators, Haya Esrar, involved in the research. 


\section{QUESTIONS ABOUT THE STUDY}

If you have any questions about the research now, please ask. If you have questions later about the research, you may contact:

1) Haya Esrar

Graduate Student

Email: haya.esrar@ryerson.ca

2) Hossein Zolfagharinia

Graduate Student Supervisor, Assistant Professor, Global Management Studies

Tel: 416-979-5000 ext.7532

Email:h.zolfagharinia@ryerson.ca

This study has been reviewed by the Ryerson University Research Ethics Board. If you have questions regarding your rights as a participant in this study, please contact:

Research Ethics Board

c/o Office of the Vice President, Research and Innovation

Ryerson University

350 Victoria Street

Toronto, ON M5B 2K3

416-979-5042

rebchair@ryerson.ca

\section{THESIS RESEARCH - IDENTIFYING STRATEGIES TO MITIGATE EXCESS SEASONAL INVENTORY}

CONFIRMATION OF AGREEMENT

Your signature below indicates that you have read the information in this agreement and have had a chance to ask any questions you have about the study. Your signature also indicates that you agree to participate in the study and have been told that you can change your mind and withdraw your consent to participate at any time. You have been given a copy of this agreement. You have been told that by signing this consent agreement you are not giving up any of your legal rights.

Name of Participant (please print)

Signature of Participant

Date 
I agree to be audio recorded for the purposes of this study. I understand how these recordings will be stored and destroyed.

Signature of Participant

Date 


\title{
Appendix E - Coder Agreement Form
}

\author{
Ryerson \\ University \\ RYERSON UNIVERSITY \\ Pledge of Confidentiality
}

$\mathrm{I}$, , through my involvement with and work on

Identifying Strategies to Mitigate Excess Seasonal Inventory will have access to data which contains confidential information that respondents generally perceive as personal and private. I understand that access to this confidential information and data carries with it responsibility to guard against unauthorized use. To treat information as confidential means to not divulge it or make it accessible to anyone who is not a project member. Such a disclosure would violate the confidentiality promised to participants and would violate University ethics policies.

I agree to fulfill my responsibilities on this project in accordance with the following:

1. I agree to not permit non-project personnel access to the data, either electronically, in hard copy, or orally.

2. I agree to not make any copies of the data that I will be given access to.

3. I agree to not attempt to identify individuals, or institutions.

4. I agree that in the event I inadvertently uncover the identity of an individual, or institution, I will maintain the highest level of confidentiality of this information, make no use of the knowledge and inform the study's Principal Investigator.

\section{QUESTIONS}

If you have any questions, please ask. If you have questions later, you may contact the Principal Investigator and/or Supervisor:

3) Haya Esrar (Principal Investigator)

Graduate Student

Email: haya.esrar@ryerson.ca

4) Hossein Zolfagharinia

Graduate Student Supervisor, Assistant Professor, Global Management Studies

Tel: 416-979-5000 ext.7532

Email: h.zolfagharinia@ryerson.ca

CONFIRMATION OF AGREEMENT

Your signature below indicates that you have read the information in this agreement and have had a chance to ask any questions you have. You have been told that by signing this consent agreement you are not giving up any of your legal rights. 


\section{References}

Atieno, O. P. (2013). An Analysis of the Strengths and Limitation of Qualitative and Quantitative Research Paradigms. Problems of Education in the 21st Century, 13, 13-18.

Aye, G. C., Balcilar, M., Gupta, R., \& Majumdar, A. (2015). Forecasting aggregate retail sales: The case of south africa. International Journal of Production Economics, 160, 66-79. doi:10.1016/j.ijpe.2014.09.033

Bartlett, P. A., Julien, D. M., \& Baines, T. S. (2007). Improving supply chain performance through improved visibility. The International Journal of Logistics Management, 18(2), 294-313. doi:10.1108/09574090710816986

Bhattacharya, R., \& Bandyopadhyay, S. (2011). A review of the causes of bullwhip effect in a supply chain. The International Journal of Advanced Manufacturing Technology, 54(912), 1245-1261. doi:10.1007/s00170-010-2987-6

Bolić, M., Athalye, A., \& Li, T. H. (2010). Performance of Passive UHF RFID Systems in Practice. In RFID Systems (pp. 1-22). Wiley-Blackwell. Doi:10.1002/9780470665251

Bowen, G. A. (2009). Document Analysis as a Qualitative Research Method. Qualitative Research Journal, vol. 9, (2), 27-40. doi:10.3316/QRJ0902027

Bowersox, D.J., Closs, D.J. and Cooper, M.B. (2007), Supply Chain Logistics Management, $2^{\text {nd }}$ ed., McGraw-Hill, New York, NY.

Braun, V., \& Clarke, V. (2006). Using thematic analysis in psychology. Qualitative Research in Psychology, 3(2), 77-101. doi:10.1191/1478088706qp063oa

Cachon, G. (2004). The Allocation of Inventory Risk in a Supply Chain: Push, Pull, and Advance-Purchase Discount Contracts. Management Science, 50(2), 222-238. doi: $10.1287 / \mathrm{mnsc} .1030 .0190$ 
Cai, J., Liu, X., Xiao, Z., \& Liu, J. (2009). Improving supply chain performance management: A systematic approach to analyzing iterative KPI accomplishment. Decision Support Systems, 46(2), 512-521. doi:10.1016/j.dss.2008.09.004

Challenges in Supply Chain Visibility. (2014, November 12). Retrieved from https://www.ibm.com/support/knowledgecenter/SS73C3/com.ibm.help.scv_buyer_ug.doc /scv_challenges_in_supplychain_visibility.html?view=embed

Chen, F., Drezner, Z., Ryan, J. K., \& Simchi-Levi, D. (2000). Quantifying the Bullwhip Effect in a Simple Supply Chain: The Impact of Forecasting, Lead Times, and Information. Management Science, 46(3), 436-443.

Cho, D. W., \& Lee, Y. H. (2013). The value of information sharing in a supply chain with a seasonal demand process. Computers \& Industrial Engineering, 65(1), 97-108. doi: 10.1016/j.cie.2011.12.004

Cho, S. (2018). What is Seasonal Inventory \& 4 Ways to Deal with Seasonal Inventory. Retrieved from https://emergeapp.net/sales/seasonal-inventory/

Choi, Y., Kang, D., Chae, H., \& Kim, K. (2008). An enterprise architecture framework for collaboration of virtual enterprise chains. The International Journal of Advanced Manufacturing Technology, 35(11-12), 1065-1078. DOI 10.1007/s00170-006-0789-7

Chopra, S., \& Meindl, P. (2010). Understanding the Supply Chain. In Supply Chain Management: strategy, planning, \& Operation (p. 5). New Jersey: Prentice Hall.

Chou, S., \& Chang, Y. (2008). The implementation factors that influence the ERP (enterprise resource planning) benefits. Decision Support Systems, 46(1), 149-157. doi:10.1016/j.dss.2008.06.003 
Chow, H. K. H., Choy, K. L., Lee, W. B., \& Lau, K. C. (2006). Design of a RFID case-based resource management system for warehouse operations. Expert Systems With Applications, 30(4), 561-576. doi:10.1016/j.eswa.2005.07.023

Christopher, M., \& Lee, H. (2004). Mitigating supply chain risk through improved confidence. International Journal of Physical Distribution \& Logistics Management, 34(5), 388-396. doi:10.1108/09600030410545436

Closs, D. J. \& Nair, A. (2006). An examination of the impact of coordinating supply chain policies and price markdowns on short lifecycle product retail performance. International Journal of Production Economics, 102(2), 379-392. doi: 10.1016/j.ijpe.2005.04.009

Cohen, D., \& Crabtree, B. (2006). Qualitative Research Guidelines Project. http://www.qualres.org/HomeSemi-3629.html

Cook, L. S., Heiser, D. R., \& Sengupta, K. (2011). The moderating effect of supply chain role on the relationship between supply chain practices and performance. International Journal of Physical Distribution \& Logistics Management, 41(2), 104-134. doi:10.1108/09600031111118521

Cotteleer, M. J., \& Bendoly, E. (2006). Order Lead-Time Improvement following Enterprise Information Technology Implementation: An Empirical Study. MIS Quarterly, 30(3), 643-660. doi:10.2307/25148743

Creswell, J. W. (2007). Qualitative inquiry and research design: Choosing among five traditions. Thousand Oaks, CA: Sage.

D'Angelo, M. (2018, February 22). 7 Essential POS System Features for Your Retail Business. Retrieved from https:/www.business.com/articles/essential-pos-features-retail-business/ 
Daugherty, P. J., Richey, R. G., Roath, A. S., Min, S., Chen, H., Arndt, A. D., \& Genchev, S. E. (2006). Is collaboration paying off for firms? Business Horizons, 49(1), 61-70. doi: 10.1016/j.bushor.2005.06.002

deLarminat, P. (2013). Entre « quantitatif» et « qualitatif». Comment les investisseurs professionnels évaluent les gérants d'actifs financiers. L'Année sociologique, vol. 63,(1), 77-105. doi:10.3917/anso.131.0077.

DeSantis, L., \& Ugarriza, D. N. (2000). The Concept of Theme as Used in Qualitative Nursing Research. Western Journal of Nursing Research, 22(3), 351-372. https://doi.org/10.1177/019394590002200308

Deshwal, P., (2016). Customer experience quality and demographic variables (age, gender, education level, and family income) in retail stores. International Journal of Retail \& Distribution Management, 44 (9), 940-955, doi:10.1108/IJRDM-03-2016-0031

Dewa, P. K., Pujawan, N., \& Vanany, I. (2017). Human errors in warehouse operations: An improvement model. International Journal of Logistics Systems and Management, 27(3), 298-317. doi:10.1504/ijlsm.2017.084468

Diefenbach, T. (2009). Are Case Studies More Than Sophisticated Storytelling? Methodological Problems of Qualitative Empirical Research Mainly Based on Semi-Structured Interviews. Quality and Quantity, 43(6), 875-894. doi:10.4135/9781473915480.n47

Dyer, J., \& Singh, H. (1998). The Relational View: Cooperative Strategy and Sources of Interorganizational Competitive Advantage. The Academy of Management Review, 23(4), 660-679. Retrieved from http://www.jstor.org/stable/259056 
Enslow, B. (2006). Global supply chain benchmark report: industry priorities for visibility, B2B collaboration, trade compliance, and risk management (pp. 1-39, Rep.). Boston, MA: Aberdeen Group.

Forrester, J. W. (1958). Industrial Dynamics, a major breakthrough for decision makers. Harvard Business Review,36(4), 37-66.

Francis, V. (2008). Supply chain visibility: Lost in translation? Supply Chain Management: An International Journal, 13(3), 180-184. doi:10.1108/13598540810871226

Galletta, A. (2013). Mastering the semi-structured interview and beyond : from research design to analysis and publication.

Geary, S., Disney, S. M., \& Towill, D. R. (2006). On bullwhip in supply chains-historical review, present practice and expected future impact. International Journal of Production Economics, 101(1), 2-18. doi: 10.1016/j.ijpe.2005.05.009

Golafshani, N. (2003). Reliability and Validity in Qualitative Research. The Qualitative Report, 8(4), 597-606. doi:10.4135/9781412985659.n2

Guinn, J. (2018). What Is a Point of Sale System? A Guide to POS Features. Retrieved from https://www.softwareadvice.com/resources/what-is-a-point-of-sale-system/

Gunasekaran, A., \& Ngai, E. W. T. (2004). Information systems in supply chain integration and management. European Journal of Operational Research, 159(2), 269-295. doi:10.1016/j.ejor.2003.08.016

Hammarberg, K., Kirkman, M., \& Lacey, S. D. (2016). Qualitative research methods: When to use them and how to judge them. Human Reproduction, 31(3), 498-501. doi:10.1093/humrep/dev334 
Heckmann, I., Comes, T., \& Nickel, S. (2015). A critical review on supply chain risk -definition, measure and modeling. Omega, 52(Complete), 119-132. doi: 10.1016/j.omega.2014.10.004

Hendricks, K. B., \& Singhal, V. R. (2009). Demand-Supply Mismatches and Stock Market Reaction: Evidence from Excess Inventory Announcements. Manufacturing \& Service Operations Management, 11(3), 509-524. doi:10.1287/msom.1080.0237

Holweg, M., Disney, S., Holmstrom, J., \& Smaros, J. (2005). Supply chain Collaboration: Making Sense of the Strategy Continuum. European Management Journal, 23(2), 170 181. doi: 10.1016/j.emj.2005.02.008

Huang, G. Q., Lau, J. S. K., \& Mak, K. L. (2003). The impacts of sharing production information on supply chain dynamics: A review of the literature. International Journal of Production Research, 41(7) 1483-1517. doi:10.1080/0020754031000069625

Huong Tran, T. T., Childerhouse, P., \& Deakins, E. (2016). Supply chain information sharing: challenges and risk mitigation strategies. Journal of Manufacturing Technology Management, 27(8), 1102-1126. Doi: 10.1108/JMTM-03-2016-0033

Intelligent retailing: POS helps do more with less. (2018). Retrieved from https://www.ibm.com/midmarket/us/en/article_Industries3_1209.html

Interview Schedule Sample Template. (2006). Retrieved from https://www.hawaii.edu/mauispeech/pdf/interviewschedule.pdf Introduction: Collaborative Planning, Forecasting and Replenishment (CPFR). (2011, March 21). Retrieved from https://scm.ncsu.edu/scm-articles/article/introductioncollaborative-planning-forecasting-and-replenishment-cpfr-a-tutorial 
Jajja, M. S. S., Kannan, V. R., Brah, S. A., \& Hassan, S. Z. (2016). Supply chain strategy and the role of suppliers: evidence from the Indian sub-continent. Benchmarking: An International Journal, 23(7), 1658-1676. https://doi.org/10.1108/BIJ-06-2014-0058

Joshi, Y. V. (2000). Information Visibility And Its Effect On Supply Chain Dynamics. Retrieved from http://hdl.handle.net/1721.1/9052

Juneja, P. (n.d.). Characteristics, Functions and Services of a Retailer. Retrieved 2018, from https://www.managementstudyguide.com/characteristics-functions-and-services-of-aretailer.htm

Kawulich, B. B. (2005). Participant observation as a data collection method. Forum : Qualitative Social Research, 6(2).

Koçoğlu, İ., İmamoğlu, S. Z., İnce, H., \& Keskin, H. (2011). The effect of supply chain integration on information sharing: Enhancing the supply chain performance. ProcediaSocial and Behavioral Sciences, 24, 1630-1649. Doi:10.1016/j.sbspro.2011.09.016

Kontuš, E. (2014). Management of Inventory in a Company. Ekonomski Vjesnik, 27(2), 245 256.

Lampard, R., \& Pole, C. (2015). Practical social investigation: Qualitative and quantitative methods in social research.

Laosirihongthong, T., Adebanjo, D., Samaranayake, P., Subramanian, N., Boon-itt, S. (2018). Prioritizing warehouse performance measures in contemporary supply chains. International Journal of Productivity and Performance Management, 67 (9), 1703-1726. Doi: 10.1108/IJPPM:03.2018.0105

Lavrakas, P. J. (2008).Encyclopedia of survey research methods Thousand Oaks, CA: Sage Publications, Inc. doi: 10.4135/9781412963947 
Lee, H., Kim, M. S., \& Kim, K. K. (2014). Interorganizational information systems visibility and supply chain performance. International Journal of Information Management, 34 (2), 285 295. doi:10.1016/j.ijinfomgt.2013.10.003

Lee, H. L., Padmanabhan, V., \& Whang, S. (1997). THE BULLWHIP EFFECT IN SUPPLY CHAINS. Sloan Management Review, 38(3), 93.

Leung, L. (2015). Validity, reliability, and generalizability in qualitative research. $J$ Family Med Prim Care, 4 (3), 324-327. doi: 10.4103/2249-4863.161306

Lumsden, K., \& Mirzabeiki, V. (2008). Determining the value of information for different partners in the supply chain. International Journal of Physical Distribution \& Logistics Management, 38(9), 659-673. doi:10.1108/09600030810925953

Marowits, R. (2014, July 12). Women's clothing retailers face tough year ahead: Analysts. Retrieved from https://www.ctvnews.ca/business/women-s-clothing-retailers-face-toughyear-ahead-analysts-1.1910913

Maxwell, J. A. (2009). Designing a qualitative study. In L. Bickman \& D. J. Rog The SAGE handbook of applied social research methods (pp. 214-253). Thousand Oaks, CA: SAGE Publications, Inc. doi: 10.4135/9781483348858.n7

McDonald, P. (2018, April 19). Retail Supply Chain KPIs: Valuable Insights to Collaboration. Retrieved from https://www.symphonyretailai.com/knowledge-hub/retail-supply-chainkpis-valuable-insights-collaboration/

McHugh M. L. (2012). Interrater reliability: the kappa statistic. Biochemia medica, 22(3), 276 282. 
Melanie. (2017, October 6). The Problem With Seasonal Inventory On Inventory Control. Retrieved from https://www.unleashedsoftware.com/blog/problem-seasonal-inventorycontrol

Mentzer, J. T. (2001). SCM as a Set of Activities to Implement a Management Philosophy. In Supply Chain Management (p, 11). California: Sage Publications

Miksen, C. (2017, November 21). What Do Retailers Do With Surplus Inventory? Retrieved from http://smallbusiness.chron.com/retailers-surplus-inventory-36258.html

Mwencha, M., \& Rosen, J. (2016). Better Data Visibility \& Data Use Result in Lower Cost and Improved Performance in Medicine Supply Chains. Bloomberg Data for Good Exchange Conference, New York City, 2016. New York.

Nair, A. (2005). Linking manufacturing postponement, centralized distribution and value chain flexibility with performance. International Journal of Production Research, 43(3), 447463. doi:10.1080/00207540512331311886

Neuman, W. L. (2014). Social Research Methods: Qualitative And Quantitative Approaches (7thed.). Harlow, Essex: Pearson Education Limited.

Newman, I., \& Benz, C. R. (1998). Qualitative-quantitative Research Methodology : Exploring the Interactive Continuum. Carbondale, Ill: Southern Illinois University Press

Nielsen, J. (2004, March 1). Risks of Quantitative Studies. Retrieved from https://www.nngroup.com/articles/risks-of-quantitative-studies/

Noble, H., \& Smith, J. (2015). Issues of validity and reliability in qualitative research. Evidence Based Nursing, 18(2), 34. https://doi.org/10.1136/eb-2015-102054 
Oboni, F., \& Oboni, C. (2016). Let's define Strategic, Tactical and Operational planning. Retrieved from https://www.riskope.com/2014/04/03/lets-define-strategictactical-and-operational-planning/

Qrunfleh, S., \& Tarafdar, M. (2014). Supply chain information systems strategy: Impacts on supply chain performance and firm performance. International Journal of Production Economics, 147(Part B), 340-350. doi:10.1016/j.ijpe.2012.09.018

Quirk, R. E., \& Borrello, S. J. (2005). RFID: Rapid Deployment and Regulatory Challenges. Retrieved from https://www.pharmamanufacturing.com/assets/Media/ MediaManager/VenableRFIDpaper.pdf?SESSID=62935cf41f5a19909f5bb3ae3a598490

Raman, A., DeHoratius, N., \& Ton, Z. (2001). Execution: The missing link in retail operations. California Management Review, 43(3), 136-152.

Rekik, Y., Syntetos, A., \& Jemai, Z. (2015). An e-retailing supply chain subject to inventory inaccuracies. International Journal of Production Economics, 167, 139-155. doi:10.1016/j.ijpe.2015.04.011

Ryan, T. (2015, May 15). Retailers suffer the high cost of overstocks and out-of-stocks. Retrieved from https://www.retailwire.com/discussion/retailers-suffer-the-high-cost-ofoverstocks-and-out-of-stocks/

Sahay, B. S. (2003). Supply chain collaboration: The key to value creation. Work Study, 52(2), 76-83.

Sarac, A., Absi, N., \& Dauzère-Pérès, S. (2010). A literature review on the impact of RFID technologies on supply chain management. International Journal of Production Economics, 128(1), 77-95. doi:10.1016/j.ijpe.2010.07.039 
Sari, K. (2015). Investigating the value of reducing errors in inventory information from a supply chain perspective. Kybernetes, 44(2), 176-185. doi:10.1108/K-06-2014-0113

Seifert, D. (2003). Collaborative planning, forecasting, and replenishment: How to create a supply chain advantage. NY: AMACOM, a division of American Management Association.

Simatupang, T. M., Wright, A. C., \& Sridharan, R. (2002). The knowledge of coordination for supply chain integration. Business Process Management, 8(3), 289-308. doi:10.1108/14637150210428989

Shtub, A. (1999). Enterprise resource planning (erp). the dynamics of operations management. Statistics Canada. (2017). 2016 Census of Canada topic based tabulations Immigration and Ethnocultural Diversity Highlight Tables: Ethnic Origin, both sexes, age (total), Canada, 2016 Census - 25\% Sample data. (Catalogue number 98-402-X2016007). Retrieved from Statistics Canada: https://www12.statcan.gc.ca/census-recensement/2016/dp-pd/hltfst $/ \mathrm{imm} /$ Table.cfm?Lang $=\mathrm{E} \& \mathrm{~T}=31 \& \mathrm{Geo}=01$

Tajima, M. (2007). Strategic value of RFID in supply chain management. Journal of Purchasing and Supply Management, 13(4), 261-273. https://doi.org/10.1016/j.pursup.2007.11.001

Taylor, G. (2015, November 18). Overstock losses to cost retailers \$471 Billion in 2015. Retrieved from https://www.retailtouchpoints.com/topics/inventory-merchandisingsupply-chain/overstock-losses-to-cost-retailers-471-billion-in-2015

Tersine, R. J., \& Toelle, R. A. (1984). Optimum stock levels for excess inventory items. Journal of Operations Management, 4(3), 245-258. doi:10.1016/0272-6963(84)90014-7

Trotter, C. (2016). Why Physical Retail Matters More Than Ever. Retrieved from https://retailnext.net/en/blog/why-physical-retail-matters-more-than-ever/ 
Turley, L. W., \& Chebat, J. (2002). Linking retail strategy, atmospheric design and shopping behaviour. Journal of Marketing Management, 18(1-2), 125-144. doi:10.1362/0267257022775891

Turner, S. F., Cardinal, L. B., \& Burton, R. M. (2017). Research Design for Mixed Methods: A Triangulation-based Framework and Roadmap. Organizational Research Methods, 20(2), 243-267. https://doi.org/10.1177/1094428115610808

Understanding the Power of Ethnic Consumers in Canada. (2018, February 16). Retrieved from https://www.nielsen.com/ca/en/insights/news/2018/understanding-the-power-of-ethnicconsumers-in-canada.html

Village, J., Salustri, F. A., \& Neumann, W. (2016). Cognitive mapping links human factors to corporate strategies. European Journal of Industrial Engineering, 10(1), 1. doi:10.1504/ejie.2016.075126

Wang, X., \& Disney, S. M. (2016). The bullwhip effect: Progress, trends and directions. European Journal of Operational Research, 250(3), 691-701. Doi:10.1016

Xiao, T., \& Qi, X. (2008). Price competition, cost and demand disruptions and coordination of a supply chain with one manufacturer and two competing retailers. Omega, 36(5), 741-753. doi:10.1016/j.omega.2006.02.008

Yao, Y., Evers, P. T., \& Dresner, M. E. (2007). Supply chain integration in vendor-managed inventory. Decision Support Systems, 43, 663-674. doi:10.1016bow//j.dss.2005.05.021

Yilmaz, K. (2013). Comparison of Quantitative and Qualitative Research Traditions: Epistemological, theoretical, and methodological differences. European Journal of Education, 48(2), 311-325. doi:10.1111/ejed.12014 
Yücesan, E. (2007). Impact of Information Technology on Supply Chain Management. In Trends in Supply Chain Design and Management(pp. 127-148). London, UK: Springer.

Zhang, A. N., Goh, M., \& Meng, F. (2011). Conceptual modelling for supply chain inventory visibility. International Journal of Production Economics, 133(2), 578-585.

Doi: 10.1016 /j.ijpe.2011.03.003

Zhang, C., Tan, G., Robb, D. J., \& Zheng, X. (2006). Sharing shipment quantity information in the supply chain. Omega - The International Journal of Management Science, 34(5), 427438. doi:10.1016/j.omega.2004.12.005

Zhang, G.P. (2009). Neural networks for retail sales forecasting. Business Information Systems, $2806-2810$. 